\title{
Formation of nanocrystalline graphite in polymer-derived SiCN by polymer infiltration and pyrolysis at a low temperature
}

\author{
Mingxing LI, Laifei CHENG ${ }^{*}$, Fang YE*, Conglin ZHANG, Jie ZHOU \\ Science and Technology on Thermostructural Composite Materials Laboratory, \\ Northwestern Polytechnical University, Xi'an 710072, China
}

Received: February 5, 2021; Revised: April 28, 2021; Accepted: May 17, 2021

(C) The Author(s) 2021.

\begin{abstract}
The microstructure of polymer-derived ceramics (PDCs) was closely related to processing. This study demonstrated that $\mathrm{SiCN}$ matrix prepared by polymer infiltration and pyrolysis (PIP) at $900{ }^{\circ} \mathrm{C}$ inside a $\mathrm{Si}_{3} \mathrm{~N}_{4}$ whisker $\left(\mathrm{Si}_{3} \mathrm{~N}_{4 \mathrm{w}}\right)$ preform with submicro-sized pores differed from its powderconsolidated analogue in both the content and structure of free carbon. Chemical analysis showed that PIP process had a higher free carbon yield. Raman spectroscopy and transmission electron microscopy (TEM) observation discovered a higher graphitization degree of free carbon and the existence of nanocrystalline graphite in $\mathrm{SiCN}$ matrix. Dielectric properties of $\mathrm{Si}_{3} \mathrm{~N}_{4 \mathrm{w}} / \mathrm{SiCN}$ composites were greatly enhanced when volume fraction of $\mathrm{SiCN}$ matrix reached $24.5 \%$ due to dielectric percolation caused by highly-lossy free carbon. Reconsolidation of hydrocarbon released during pyrolysis by gas-state carbonization in $\mathrm{Si}_{3} \mathrm{~N}_{4}$ whisker preform was supposed to account for the high yield and graphitization degree of free carbon in PIP process.

Keywords: polymer-derived ceramics (PDCs); silicon carbonitride ( $\mathrm{SiCN}$ ); free carbon; carbonization; dielectric property
\end{abstract}

\section{Introduction}

Silicon-based polymer-derived ceramics (PDCs) stand out among a large group of advanced ceramic materials owing to their following attractive properties. One is that due to the polymeric nature of the precursor, they can be processed using flexible polymer-processing techniques such as injection molding, extrusion, and polymer infiltration and pyrolysis (PIP) [1-3]. This is a valuable advantage since by these processing techniques, near-net shaping of ceramics or ceramic composites

\footnotetext{
* Corresponding authors.

E-mail: L. Cheng, chenglf@nwpu.edu.cn; F. Ye, yefang511@nwpu.edu.cn
}

can be performed at the absence of sintering additives which can be hardly realized by traditional route. The second one is that composition and nanostructure of silicon-based PDCs can be adjusted by molecular design of precursor and thermal treatment (curing and pyrolysis) to endow them with desirable multi-functional properties [4-6]. For instance, with a carefully tailored nanostructure, silicon carbonitrides (SiCNs) possess excellent creep resistance $[7,8]$ and oxidation resistance $[9,10]$ at high temperatures, making them ideal candidates for thermostructural materials. It has been proved that the fascinating properties of SiCNs were based on their unique microstructure in which nano-sized free carbon clusters were buried in amorphous or crystallized $\mathrm{Si}-\mathrm{C}-\mathrm{N}$ matrix $[4,11-13]$. Despite its low concentration, 
free carbon plays a key role in determining many properties, such as creep resistance, crystallization resistance, electrical conductivity, and electrochemical properties of SiCNs $[1,13,14]$. Therefore, understanding the in-situ formation mechanism and the structure evolution of free carbon is fundamental to gain deep insights into the microstructure-property relationship of SiCNs. The structure and properties of carbon materials are known to be strongly dependent on the so-called carbonization process, i.e., the changes from organic precursor to inorganic carbon. Researches based on a variety of spectroscopy methods confirmed that free carbon in SiCNs is generated from the hydrocarbon side groups that attached to the backbone of the precursor molecules [15-17]. During pyrolysis, these hydrocarbon groups undergo a decomposition process which involves the cleavage of $\mathrm{C}-\mathrm{H}$ bonds and the formation of $\mathrm{sp}^{2}$ bonds between carbon atoms. This process can be essentially regarded as a case of the well-known solid-state carbonization of thermosetting polymers, and the resulting carbon is called resin carbon. Due to thermodynamic and kinetic factors, resin carbon prepared around $800-1300{ }^{\circ} \mathrm{C}$ is generally characterized with an amorphous or a turbostratic structure [18]. Therefore, the electrical properties of this kind of carbon are much inferior to that of graphite. A further heat-treatment around $1500-3000{ }^{\circ} \mathrm{C}$, i.e., graphitization, can be applied so that growth of crystallites and improvement in stacking regularity occur. At the same time, electrical conductivity of resin carbon usually experienced a giant leap during graphitization due to decrease in energy band gap between the valence and conduction bands [18]. Take carbon fiber derived from isotropic pitch as an example. Carbon fiber carbonized at $1300{ }^{\circ} \mathrm{C}$ has an electrical conductivity of $6.7 \times 10^{3} \mathrm{~S} / \mathrm{m}$. After graphitization at $2800{ }^{\circ} \mathrm{C}$, the electrical conductivity of carbon fiber increased to $2.0 \times 10^{4} \mathrm{~S} / \mathrm{m}$ [18].

Heat-treatment has proven to be an effective method to enhance the electromagnetic properties of SiCNs. Researchers have paid a lot of attention to the optimization of dielectric properties of $\mathrm{SiCNs}$ by heat-treatment. Li et al. [19] reviewed the dielectric properties of $\mathrm{PDC}-\mathrm{Si}(\mathrm{B}) \mathrm{C}(\mathrm{N})$ materials in the literature and found that crystallized PDCs prepared by heattreatment above $1500{ }^{\circ} \mathrm{C}$ obtained superior dielectric properties to their amorphous counterparts. By heat-treatment with or without Fe catalyst $[19,20]$, they have successfully enhanced the dielectric properties of $\mathrm{SiCN}$ and $\mathrm{Si}_{3} \mathrm{~N}_{4 \mathrm{w}}$ reinforced $\mathrm{SiCN}\left(\mathrm{Si}_{3} \mathrm{~N}_{4 \mathrm{w}} / \mathrm{SiCN}\right)$. Liu et al. [21] and Xue et al. [22-24] also demonstrated the improvement of dielectric properties of $\mathrm{Si}_{3} \mathrm{~N}_{4 \mathrm{w}} / \mathrm{SiCN}$ by the adjustment of carbon content and heat-treatment of the chemical vapor deposited SiCNs. From these studies we can see that SiCNs pyrolyzed at low temperatures $\left(<1500{ }^{\circ} \mathrm{C}\right)$ generally possess dielectric properties comparable to those of an insulator due to low conductivity of amorphous carbon and $\mathrm{Si}-\mathrm{C}-\mathrm{N}$ network. Both real and imaginary permittivity $\left(\varepsilon^{\prime}\right.$ and $\varepsilon^{\prime \prime}$ ) can be greatly enhanced to obtain a favorable electromagnetic wave absorbing property after heattreatment beyond the temperature of $1500{ }^{\circ} \mathrm{C}$ mainly due to the graphitization of free carbon (resin carbon) $[25,26]$. However, this high temperature also triggered the decomposition and phase separation of the $\mathrm{Si}-\mathrm{C}-\mathrm{N}$ network, leading to micro-cracks and open pores in the materials which are detrimental to the mechanical properties and oxidation resistance of materials. This means that in order to obtain free carbon with high conductivity without the damage to those properties, other carbonization process should be considered.

Apart from the aforementioned "solid-state carbonization" route to form free carbon in SiCNs, the "gas-state carbonization" process should also be considered. Many researches have confirmed the release of gaseous hydrocarbon species $\left(\mathrm{C}_{x} \mathrm{H}_{y}\right)$ during the polymer-toceramic transitions of PDCs. Specifically, releasing of methane $\left(\mathrm{CH}_{4}\right)$ was found to be a common event in the temperature range between 400 and $800{ }^{\circ} \mathrm{C}$ of pyrolysis for a variety of polysilazane precursors with different molecular structures [6,27-29]. What is worth paying attention to is that the nature of the free carbon produced by the gas-state carbonization process can be quite different from that of resin carbon. For example, using $\mathrm{CH}_{4}$ as the precursor, the carbon material pyrolyzed at relatively low temperatures $\left(800-1000{ }^{\circ} \mathrm{C}\right)$ exhibits a much higher degree of crystallinity than that of resin carbon pyrolyzed at the same temperature range [30,31]. This means that if the hydrocarbon released during pyrolysis can be reconsolidated into carbon materials, free carbon with high degree of crystallinity can be obtained in SiCNs prepared at a low temperature. However, in most cases, microstructure characterization basically revealed a highly amorphous nature of carbon in $\mathrm{SiCNs}$ with low pyrolysis temperatures $\left(<1500{ }^{\circ} \mathrm{C}\right)$, suggesting that the content of carbon produced by gas-state carbonization is extremely low, if not zero. This study aims to discuss the possibility to produce free carbon in $\mathrm{SiCN}$ through 
a gas-state carbonization. The basic idea is that when $\mathrm{SiCN}$ was prepared as the matrix materials in a porous preform by PIP, (1) densification and pore-sealing by the introduction of $\mathrm{SiCN}$ matrix and (2) pores and cracks inside the newly fabricated matrix lead to the fact that pore-structure and surface area of the composite evolve with the repeated PIP cycles. This may affect the kinetic factors of gas-state carbonization since the diffusion, decomposition, and deposition process can be altered by the pore-structure of the preforms.

\section{Experimental}

\section{1 Material preparation}

$\mathrm{Si}_{3} \mathrm{~N}_{4 \mathrm{w}}$ ( $\beta$ phase, fabricated in-house) preforms were prepared by aqueous gel-casting process. First, low viscosity $\mathrm{Si}_{3} \mathrm{~N}_{4 \mathrm{w}}$ slurry with a whisker loading of $40 \mathrm{vol} \%$ was obtained by dispersing the whisker in a pre-mixed solution (distilled water, tetramethylammonium hydroxide, and ammonium polyacrylate) through ball-milling for 4-8 h. After the monomer (acrylamide, AM) and crosslinking agent $\left(N, N^{\prime}-\right.$ methylenebisacrylamide, MBAM) were added, the slurry was ball milled for another $1 \mathrm{~h}$. Before casting, ammonium persulphate (APS) was added into the slurry to initiate the crosslinking between AM and MBAM. The slurry was then stirred under vacuum for 2 min to disperse APS and degas at the same time. Finally, the slurry was poured into a mold $(55 \mathrm{~mm} \times$ $45 \mathrm{~mm} \times 6.5 \mathrm{~mm}$ ), which was then held in an oven at $80{ }^{\circ} \mathrm{C}$ for $30 \mathrm{~min}$ to finish the gelation process. The gel-casted green body was demolded and dried for $72 \mathrm{~h}$. Binder removal was conducted in air at $600{ }^{\circ} \mathrm{C}$ for $4 \mathrm{~h}$ with a heating rate of $1{ }^{\circ} \mathrm{C} / \mathrm{min}$. The final product was a free standing $\mathrm{Si}_{3} \mathrm{~N}_{4 \mathrm{w}}$ preform free of additives.

A commercial polysilazane (PSZ; PSZ-50, Astech, China) with a formal composition $\left[\mathrm{Si}\left(\mathrm{CH}_{3}\right) \mathrm{CH}=\mathrm{CH}_{2}-\right.$ $\left.\mathrm{NH}-\mathrm{Si}\left(\mathrm{CH}_{3}\right) \mathrm{H}-\mathrm{NH}\right]_{n}$ was used as the precursor for $\mathrm{SiCN}$. SiCN matrix was prepared inside the pores of $\mathrm{Si}_{3} \mathrm{~N}_{4 \mathrm{w}}$ preform by PIP process described as follows: $\mathrm{Si}_{3} \mathrm{~N}_{4 \mathrm{w}}$ preform was impregnated in the PSZ/xylene solution under vacuum for $2 \mathrm{~h}$ to realize the infiltration of the precursor. The samples were then filled in a corundum tube with a diameter of $50 \mathrm{~mm}$ and heated in a tube furnace at $5{ }^{\circ} \mathrm{C} / \mathrm{min}$ under flowing $\mathrm{N}_{2}$ (the $\mathrm{N}_{2}$ flow rate was $60 \mathrm{~mL} / \mathrm{min}$ ) up to $300{ }^{\circ} \mathrm{C}$ for $2 \mathrm{~h}$ and $900{ }^{\circ} \mathrm{C}$ for $2 \mathrm{~h}$ for the crosslinking and pyrolysis of the precursor, respectively, to complete a PIP cycle.
The PIP cycle was repeated 1-4 times, yielding $\mathrm{Si}_{3} \mathrm{~N}_{4 \mathrm{w}} / \mathrm{SiCN}$ composites with different densities. The concentration of PSZ in the solution was $50 \mathrm{wt} \%$ except for the first PIP cycle in which $25 \mathrm{wt} \% \mathrm{PSZ}$ were used to avoid sample cracking during pyrolysis. Composites prepared by $n(n=1,2,3,4)$ cycles of PIP were designated as $\mathrm{Si}_{3} \mathrm{~N}_{4 \mathrm{w}} / \mathrm{SiCN}-n$.

To study the dielectric properties of the reinforcement $\left(\mathrm{Si}_{3} \mathrm{~N}_{4 \mathrm{w}}\right)$ and matrix $(\mathrm{SiCN})$ as a function of their volume fraction, porous $\mathrm{Si}_{3} \mathrm{~N}_{4}$ and $\mathrm{SiCN}$ ceramics with various porosity were prepared. The preparation method of porous $\mathrm{Si}_{3} \mathrm{~N}_{4}$ ceramics by pressureless sintering can be found in Ref. [32]. Porosity control was realized by applying different amount of pore-forming agent (phenolic resin) so that various relative densities of the $\mathrm{Si}_{3} \mathrm{~N}_{4}$ green bodies were obtained. Part of the porous $\mathrm{Si}_{3} \mathrm{~N}_{4}$ samples also underwent 1 PIP cycle following the same procedure described above using $50 \mathrm{wt} \% \mathrm{PSZ}$ solution, to obtain $\mathrm{Si}_{3} \mathrm{~N}_{4} / \mathrm{SiCN}$ composites. Porous $\mathrm{SiCN}$ ceramics were prepared by powder consolidation route as follows: Crosslinked PSZ was pulverized by a corundum pestle and mortar to pass through a 60 -mesh sieved. For a typical patch, $4 \mathrm{~g}$ PSZ powder was mixed with $0.64 \mathrm{~g} 50 \mathrm{wt} \% \mathrm{PSZ}$ solution as binder and formed by uniaxial pressing in a $75 \mathrm{~mm} \times 15 \mathrm{~mm}$ stainless steel die at $200 \mathrm{MPa}$. The PSZ compactions were subsequently transformed into a tube furnace to finish the precursor to ceramic conversion following the same heating procedure as the PIP process. The samples were hereinafter referred to as powder-consolidated $\mathrm{SiCN}$ to distinguish it from $\mathrm{SiCN}$ matrix prepared by PIP. In order to tune the porosity of $\mathrm{SiCN}$, different forming pressure was applied during the compaction of PSZ powder.

\section{2 Characterization and testing}

The pyrolysis process of the crosslinked PSZ was monitored by a simultaneous thermal analysis device (STA 409 PC/PG, Netzsch, Germany) coupled with a quadrupole mass spectrometer (QMS 403, Netzsch, Germany) for the detection of mass loss and release of gaseous species. The samples were heated up from room temperature to $1000{ }^{\circ} \mathrm{C}$ at a heating rate of $10{ }^{\circ} \mathrm{C} / \mathrm{min}$ under flowing nitrogen $(99.999 \%$ pure) at a rate of $20 \mathrm{~mL} / \mathrm{min}$ in corundum crucibles. Weights of the samples relative to the weight of the empty crucible were measured by a balance accuracy of $5 \mu \mathrm{g}$. QMS 403 allows the analysis of gaseous products by ionization and the data obtained were processed using 
the NETZSCH analysis software. Two samples were used for this analysis: the PSZ powder and $\mathrm{Si}_{3} \mathrm{~N}_{4 \mathrm{w}} / \mathrm{SiCN}-2$ infiltrated with PSZ. These samples were crosslinked at $300{ }^{\circ} \mathrm{C}$ for $2 \mathrm{~h}$ following the procedure described in Section 2.1 before the thermal analysis. After crosslinking, PSZ powder was pulverized with a corundum motor and pestle, and sieved through a 60 -mesh screen. $11.42 \mathrm{mg}$ PSZ powder was used in the thermal analysis. While $\mathrm{Si}_{3} \mathrm{~N}_{4 \mathrm{w}} / \mathrm{SiCN}-2$ infiltrated with PSZ was machined into small pieces of $\sim 2 \mathrm{~mm} \times 2 \mathrm{~mm} \times 3 \mathrm{~mm}$ so that they fit into the corundum crucibles. $22.27 \mathrm{mg}$ $\mathrm{Si}_{3} \mathrm{~N}_{4 \mathrm{w}} / \mathrm{SiCN}-2$ infiltrated with PSZ was used in the thermal analysis. Bulk density and open porosity of samples were measured by Archimedes method. Mercury intrusion porosimetry (AutoPore IV 9500, Micromeritics, USA) was conducted to evaluate the pore size distribution of samples. Chemical composition of the samples was measured by a carbon/sulfur analyzer (EMIA 320V, Horiba, Japan) for carbon content and a nitrogen/oxygen analyzer (EMGA 620V, Horiba, Japan) for nitrogen and oxygen content. The silicon content of samples was determined as the difference between $100 \%$ and weight percent of $\mathrm{C}, \mathrm{N}$, and $\mathrm{O}$ considering that content of hydrogen element was usually below 1 wt $\%$. Phase composition was studied by X-ray powder diffraction (XRD, X' Pert Pro, Philips, the Netherlands). Microstructure of the samples was observed by scanning electron microscopy (SEM, Verios G4, FEI Co., USA) and transmission electron microscopy (TEM, Themis Z, FEI Co., USA). Structure of the free carbon was studied by Raman spectroscopy (inVia, Renishaw, UK; $\lambda=532 \mathrm{~nm})$. Complex permittivity $\left(\varepsilon_{\mathrm{r}}=\varepsilon_{\mathrm{r}}^{\prime}-\mathrm{j} \varepsilon_{\mathrm{r}}^{\prime \prime}\right)$ was measured by a vector network analyzer (VNA, MS4644A, Japan) in X band (8.2-12.4 GHz).

\section{Results and discussion}

\section{1 Microstructure of $\mathrm{Si}_{3} \mathrm{~N}_{4 \mathrm{w}} / \mathrm{SiCN}$}

Table 1 shows the chemical composition of PSZ precursor calculated by its formal molecular structure as well as that measured by chemical analysis. Previous study [25] showed that pyrolysis of the PSZ precursor at $900{ }^{\circ} \mathrm{C}$ yields an amorphous $\mathrm{SiCN}$ ceramic with a composition of $\mathrm{SiC}_{0.95} \mathrm{~N}_{0.98} \mathrm{O}_{0.12}$. In order to study the pyrolysis behaviors of crosslinked PSZ powder as well as that of PSZ inside the porous $\mathrm{Si}_{3} \mathrm{~N}_{4 \mathrm{w}} / \mathrm{SiCN}$ composites, thermal gravimetric (TG) analysis coupled with mass spectroscopy (MS) characterizations of these two samples was conducted. The results are shown in Fig. 1.

Note that since spectra shown in Fig. 1(b) were obtained from the sample containing both PSZ and thermally stable $\mathrm{Si}_{3} \mathrm{~N}_{4} / \mathrm{SiCN}$ composites in which only PSZ (accounting for $\sim 7 \%$ of the sample mass) underwent

Table 1 Calculated and measured chemical compositions of PSZ precursor

\begin{tabular}{|c|c|c|c|c|c|}
\hline & \multicolumn{5}{|c|}{ Chemical composition (wt\%) } \\
\hline & $\mathrm{Si}$ & $\mathrm{C}$ & $\mathrm{N}$ & $\mathrm{O}$ & $\mathrm{H}$ \\
\hline Calculated by molecular structure & 38.92 & 33.29 & 19.41 & - & 8.38 \\
\hline Measured & n.d. & $31.62 \pm 0.24$ & $21.69 \pm 0.83$ & $2.07 \pm 0.14$ & n.d. ${ }^{*}$ \\
\hline
\end{tabular}

n.d., not determined.
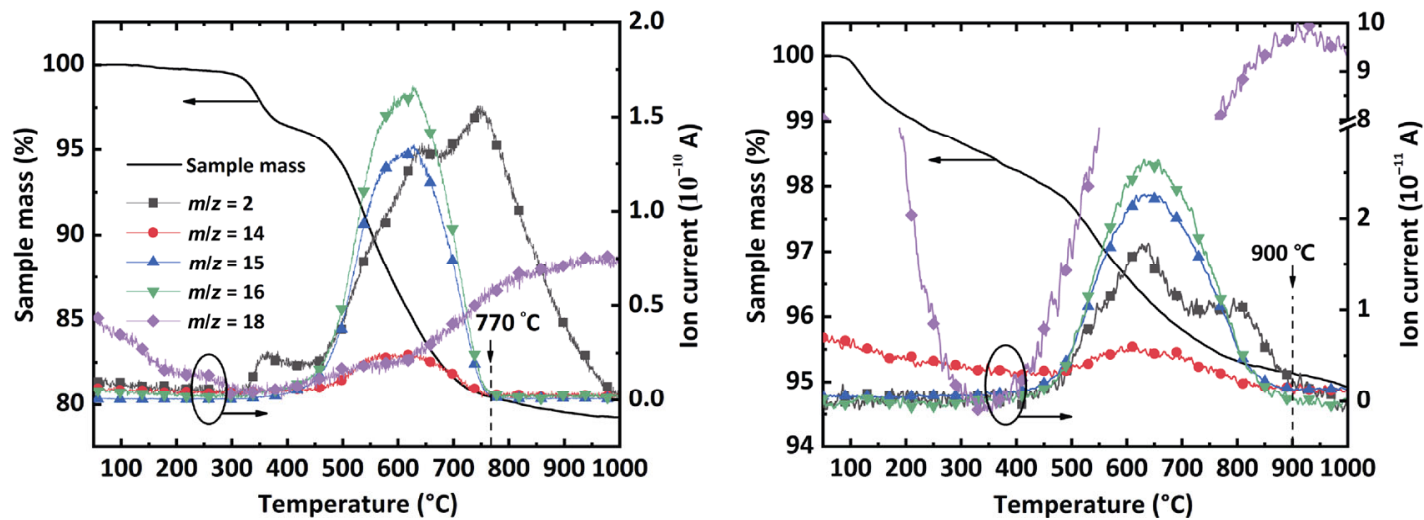

Fig. 1 TG-MS analysis of crosslinked (a) PSZ powder and (b) PSZ inside the porous $\mathrm{Si}_{3} \mathrm{~N}_{4 \mathrm{w}} / \mathrm{SiCN}-2$ composites (prepared by 2 cycles of PIP) pyrolyzed under Ar atmosphere. Hydrogen $(\mathrm{m} / \mathrm{z}=2)$, methane $(\mathrm{m} / \mathrm{z}=16)$ along with its fragments, $\mathrm{CH}_{3} \cdot(\mathrm{m} / z=$ 15), $\mathrm{CH}_{2} \cdot(m / z=14)$, and $\mathrm{H}_{2} \mathrm{O}(m / z=18)$ were detected. 
the pyrolyzing process, mass loss and ion current of the volatile species were substantially low compared with that in Fig. 1(a). Nevertheless, they should be informative for the analysis of thermolysis behaviors of PSZ inside a porous environment. Following Ref. [27], strong signals of a species with $\mathrm{m} / z=18$ were attributed to water elimination from the alumina crucibles rather than the samples and thus were not discussed hereafter. Note that significant weight loss started to occur around $100{ }^{\circ} \mathrm{C}$ only for PSZ inside the porous $\mathrm{Si}_{3} \mathrm{~N}_{4 \mathrm{w}} / \mathrm{SiCN}-2$ composites. This may be the result of water/oxygen desorption since both PSZ and SiCN [33] were sensitive to water/oxygen in the atmosphere. The mass spectroscopy in Fig. 1(b) showed that the signal of water $(m / z=18)$ accompanied this weight loss. This could be an evidence of our explanations. For both samples, significant weight loss occurred around $450{ }^{\circ} \mathrm{C}$ accompanied with the releasing of gas species with $\mathrm{m} / \mathrm{z}=2,14,15$, and 16 which were attributed to hydrogen $\left(\mathrm{H}_{2}\right)$, methane $\left(\mathrm{CH}_{4}\right)$ and its fragments $\left(\mathrm{CH}_{2}\right.$ and $\left.\mathrm{CH}_{3}\right)$. The most outstanding difference in pyrolysis behaviors between these two samples was that the releasing of hydrocarbons became trivial beyond $770{ }^{\circ} \mathrm{C}$ for PSZ powder sample, while for PSZ inside the porous composite, this out-gassing continued up to $900{ }^{\circ} \mathrm{C}$. Since gas releasing processes were fundamental in determining the elemental and phase composition of PSZ derived SiCN ceramics, this difference indicates that $\mathrm{SiCN}$ prepared by powder consolidation process and PIP process may possess different composition, microstructure, and thus dielectric properties.

Figure 2 shows the microstructure of the $\mathrm{Si}_{3} \mathrm{~N}_{4 \mathrm{w}}$, the whisker preform, and the composites. The whiskers exhibit an elongated columnar structure. In the preform, whiskers are distributed in a random order without a preferred orientation, leaving numerous inter-connected pores between the whiskers. During PIP densification process, these pores serve as diffusion channels for the volatile species.

Table 2 summarizes the weight gain after PIP in relation to the preform, bulk density, and open porosity
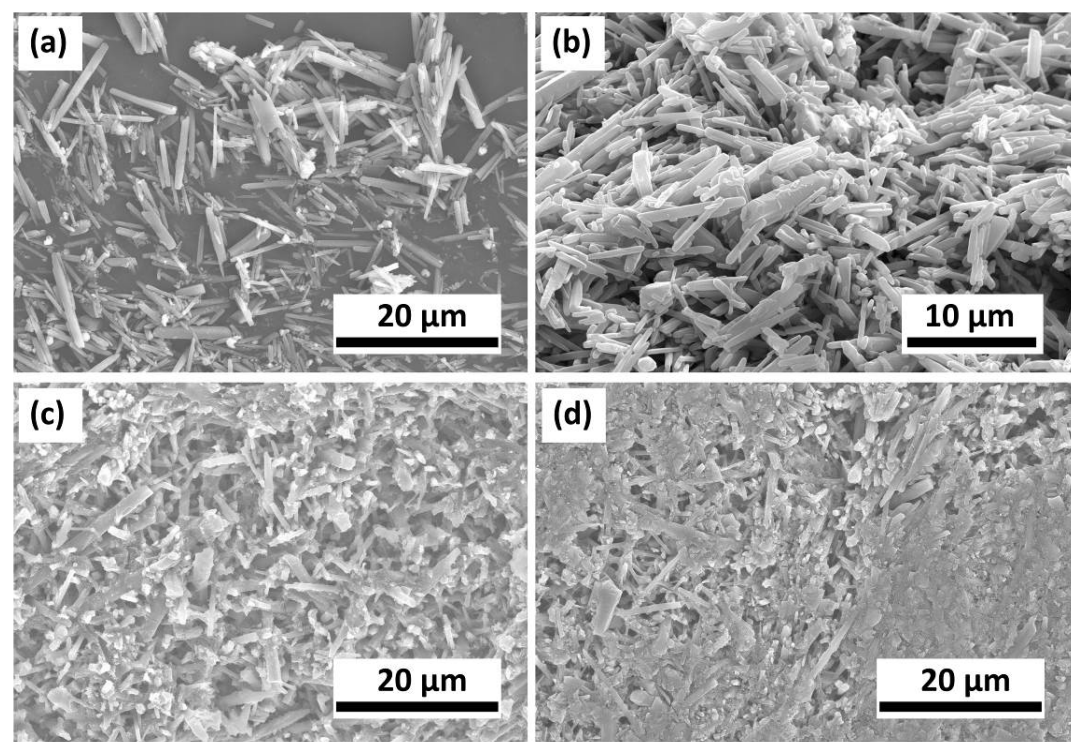

Fig. 2 SEM micrographs of (a) $\mathrm{Si}_{3} \mathrm{~N}_{4 \mathrm{w}}$, (b) whisker preform, and (c, d) cross-sections of $\mathrm{Si}_{3} \mathrm{~N}_{4 \mathrm{w}} / \mathrm{SiCN}-2$ and $\mathrm{Si}_{3} \mathrm{~N}_{4 \mathrm{w}} / \mathrm{SiCN}-4$, respectively.

Table 2 Weight gain after PIP in relation to the preform, bulk density, open porosity, and carbon content of samples

\begin{tabular}{ccccc}
\hline Sample & Weight gain (\%) & Bulk density $\left(\mathrm{g} / \mathrm{cm}^{3}\right)$ & Open porosity $(\%)$ & Volume fraction of SiCN $^{*}(\%)$ \\
\hline $\mathrm{Si}_{3} \mathrm{~N}_{4 \mathrm{w}}$ preform & - & $1.45 \pm 0.01$ & $55.4 \pm 1.0$ & 0 \\
$\mathrm{Si}_{3} \mathrm{~N}_{4 \mathrm{w}} / \mathrm{SiCN}-1$ & $10.9 \pm 0.2$ & $1.62 \pm 0.02$ & $50.0 \pm 0.7$ & $7.7 \pm 2.2$ \\
$\mathrm{Si}_{3} \mathrm{~N}_{4 \mathrm{w}} / \mathrm{SiCN}-2$ & $24.8 \pm 0.1$ & $1.85 \pm 0.01$ & $38.5 \pm 1.6$ & $17.5 \pm 1.3$ \\
$\mathrm{Si}_{3} \mathrm{~N}_{4 \mathrm{w}} / \mathrm{SiCN}-3$ & $31.7 \pm 0.7$ & $2.00 \pm 0.01$ & $32.2 \pm 0.2$ & $24.5 \pm 2.1$ \\
$\mathrm{Si}_{3} \mathrm{~N}_{4 \mathrm{w}} / \mathrm{SiCN}-4$ & $37.9 \pm 0.6$ & $2.08 \pm 0.02$ & $27.5 \pm 2.1$ & $28.5 \pm 2.7$ \\
\hline
\end{tabular}

${ }^{*}$ Volume fraction of $\mathrm{SiCN}$ was calculated as $v_{\mathrm{SiCN}}=\left(\rho_{\text {composite }}-\rho_{\text {preform }}\right) / \rho_{\mathrm{SiCN}}$, where $\rho_{\text {composite, }}, \rho_{\text {preform }}$ are the bulk densities of the composite and the preform, respectively, $\rho_{\mathrm{SiCN}}$ is the volumetric mass density of $\mathrm{SiCN}$ ceramic and its value was measured as $2.21 \mathrm{~g} / \mathrm{cm}^{3}$ by pycnometry. 
of samples. During densification by PIP, the pores inside the materials were gradually filled by $\mathrm{SiCN}$ matrix, yielding denser composites with lower open porosities. Cross-sections of the composites are presented in Figs. 2(c) and 2(d). These SEM observations revealed a progressive densification behavior. That is, volume fraction and size of the internal pores decreased with increasing number of PIP cycles which was in consistency with the data in Table 2.

Evolution of pore structure during PIP is presented in Fig. 3. With the introduction of $\mathrm{SiCN}$ matrix into the composites, not only the porosity, but also the pore-radius gradually evolved. This evolution was quantitatively characterized by mercury intrusion porosimetry. Mercury intrusion-extrusion curves (Fig. 3(a)) show that hysteresis existed between intrusion and extrusion, and considerable amount of mercury was entrapped in the pore space when pressure was removed, especially for samples with higher density $\left(\mathrm{Si}_{3} \mathrm{~N}_{4 \mathrm{w}} / \mathrm{SiCN}-2\right.$ and $\left.\mathrm{Si}_{3} \mathrm{~N}_{4 \mathrm{w}} / \mathrm{SiCN}-4\right)$. This phenomenon was called the ink-bottle effect [34], meaning that a large amount of pore space was connected to the surface through narrow necks. These narrow necks may play a decisive role in the diffusion of gaseous species produced during the pyrolysis. Figure 3(b) shows pore-size distribution of samples. Note that pore-size measured by mercury intrusion porosimetry is smaller than that observed in Fig. 2, where pores of several microns can be found. This is the result of the ink-bottle effect of mercury intrusion porosimetry so that the measured size is actually the size of the narrow throat of the interconnected channels. Nevertheless, the results obtained by mercury intrusion porosimetry were intuitive for our further analysis because the rate gas diffusion through inter-connected channels was determined by the size of the narrow throat. $\mathrm{Si}_{3} \mathrm{~N}_{4 \mathrm{w}}$ preform and the composites all exhibited narrow pore-size distribution due to the uniform distribution of whiskers in the preform. The pore diameter of the preform was in the range of $40-680 \mathrm{~nm}$. $\mathrm{Si}_{3} \mathrm{~N}_{4 \mathrm{w}} / \mathrm{SiCN}-1$ had no pores smaller than $180 \mathrm{~nm}$, meaning that when $d<d_{1}=$ $180 \mathrm{~nm}$, pores would be filled by SiCN matrix by only one PIP cycle. When $d_{1}<d<d_{2}=280 \mathrm{~nm}$, pores can be eliminated in the next PIP cycle. However, pores with $d_{2}<d<d_{3}=680 \mathrm{~nm}$ always existed even after four cycles of PIP, and the upper limit of pore diameter $\left(d_{3}\right)$ and the peak position of pore-size distribution $\left(d_{3}=680 \mathrm{~nm}\right)$ stayed almost unchanged from the first to the forth PIP cycle, indicating that larger pores with a diameter in this range were filled much more slowly compared with smaller pores. As a contrast, the size of pore in the powder-consolidated $\mathrm{SiCN}$ was within the range of $6-50 \mu \mathrm{m}$ [25]. Figure 3(c) is an illustration of
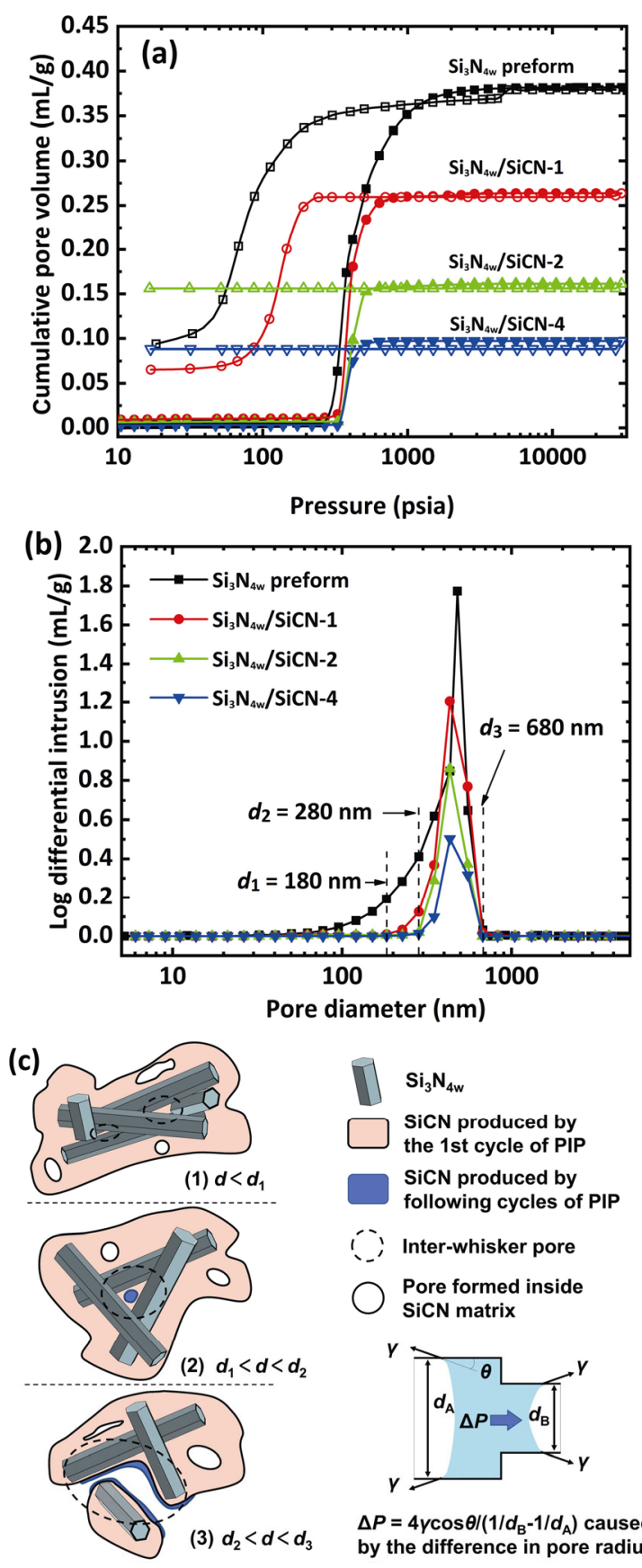

$\Delta P=4 y \cos \theta /\left(1 / d_{B}-1 / d_{A}\right)$ caused by the difference in pore radius

Fig. 3 (a) Cumulative pore volume versus pressure (filled symbols and open symbols stand for intrusion curves and extrusion curves, respectively) and (b) pore-diameter distribution obtained by mercury intrusion porosimetry. (c) Schematic of the pore-structure evolution of samples during PIP. $d$, pore diameter; $\Delta P$, capillary pressure caused by the difference in pore radius; $\gamma$, surface tension; $\theta$, wetting angle. 
the pore-structure evolution. The random stacking of $\mathrm{Si}_{3} \mathrm{~N}_{4}$ whiskers left pores with a diameter ranging from 40 to $680 \mathrm{~nm}$. These pore spaces were completely filled by precursor solution after the infiltration process which stayed within them in the following process due to surface tension. For a cylindrical capillary tube, the pressure $(P)$ on the liquid originated from surface tension can be expressed by [35]:

$$
P=4 \gamma \cos \theta / d
$$

where $\gamma$ is the surface tension of the liquid, $\theta$ is the wetting angle between the liquid and the surface of the capillary tube, and $d$ is the diameter of the capillary tube, following Young-Laplace equation. When two cylindrical tubes with different diameter were connected, the difference in the internal pressure $(\Delta P)$ is

$$
\Delta P=4 \gamma \cos \theta /\left(1 / d \mathrm{~B}-1 / d_{\mathrm{A}}\right)
$$

where $d_{\mathrm{A}}$ and $d_{\mathrm{B}}$ are the diameters of these two capillary tubes. After precursor infiltration, the samples were subjected to heating process for precursor-ceramic conversion. In this heating process, precursor solution filling the pores underwent volume shrinkage due to the evaporation of the solvent and pyrolysis the precursor. The existence of $\Delta P$ means that when voids inside the composites appeared due to the volume shrinkage, precursor and the pyrolyzed mid-products tended to be transferred to the pores with a smaller curvature through (a) liquid phase flow of the precursor (solution or melt) and (b) the vicious flow of pyrolyzed mid-products [36] under high temperature. This may explain why smaller pores $\left(d<d_{2}\right)$ quickly disappeared after 1 or 2 cycles of PIP. The pore-structure of powder-consolidated $\mathrm{SiCN}$ has been demonstrated in our previously study [25]. Since the compaction of PSZ powder (the diameter of powder was hundreds of microns) leaves large inter-connected pores, the interparticle pores within powder-consolidated $\mathrm{SiCN}$ were tens to hundreds of microns in size, which provide better gas permeability than that of $\mathrm{Si}_{3} \mathrm{~N}_{4 \mathrm{w}} / \mathrm{SiCN}$.

Table 3 provides the chemical composition of samples. When the composition of $\mathrm{Si}_{3} \mathrm{~N}_{4 \mathrm{w}}$ and the weight fraction of $\mathrm{SiCN}$ matrix in the composite were determined, the chemical composition of SiCN matrix can be calculated by

$$
\omega_{i, \mathrm{~m}}=\frac{\omega_{i, \mathrm{comp}}-(1-w) \omega_{i, \text { whisker }}}{w}
$$

where $\omega_{i, \mathrm{~m}}$ and $\omega_{i, \text { comp }}$ are the weight fraction of element $i$ of the SiCN matrix and the composite, respectively, and $w$ is the weight fraction of $\mathrm{SiCN}$ matrix in the composite. Table 3 shows that there is an obvious difference in the chemical composition between the powder-consolidated $\mathrm{SiCN}$ and the $\mathrm{SiCN}$ matrix. The latter possessed a higher content of $\mathrm{C}$ element. Previous study revealed that in PDCs-SiCN, all $\mathrm{O}$ and $\mathrm{N}$ atoms were bonded to Si while part of the $\mathrm{C}$ atoms were bonded to $\mathrm{Si}$, leaving the excess $\mathrm{C}$ forming free carbon phase [4]. Following this principle, the composition of thermodynamically stable phase PDCs-SiCN can be determined, and the general formula of PDCs-SiCN can be expressed as $\mathrm{Si}_{3+x+z / 2} \mathrm{C}_{x+y} \mathrm{~N}_{4} \mathrm{O}_{z}$ in which $x, y$, and $z / 2$ are a measure of the molar quantity of $\mathrm{SiC}$ phase, free carbon phase, and $\mathrm{SiO}_{2}$ phase,

\begin{tabular}{|c|c|c|c|c|c|c|c|c|c|}
\hline \multirow{2}{*}{ Sample } & \multicolumn{4}{|c|}{ Chemical composition (wt\%) } & \multirow{2}{*}{$\begin{array}{c}\text { Weight } \\
\text { fraction of } \\
\mathrm{SiCN} \text { matrix } \\
\text { in composite } \\
(\mathrm{wt} \%)\end{array}$} & \multicolumn{4}{|c|}{$\begin{array}{l}\text { Calculated chemical composition } \\
\text { of the SiCN matrix (wt\%) }\end{array}$} \\
\hline & $\mathrm{Si}^{\mathrm{a}}$ & $\mathrm{C}$ & $\mathrm{N}$ & $\mathrm{O}$ & & $\mathrm{Si}$ & $\mathrm{C}$ & $\mathrm{N}$ & $\mathrm{O}$ \\
\hline $\mathrm{Si}_{3} \mathrm{~N}_{4}$ whisker & - & 0 & $40.12 \pm 0.24$ & $1.32 \pm 0.01$ & & & - & & \\
\hline $\begin{array}{l}\text { Powder-conso- } \\
\text { lidated SiCN }\end{array}$ & $50.98 \pm 2.44$ & $20.73 \pm 1.36$ & $24.9 \pm 0.85$ & $3.39 \pm 0.23$ & & & - & & \\
\hline $\mathrm{Si}_{3} \mathrm{~N}_{4 \mathrm{w}} / \mathrm{SiCN}-1$ & $57.51 \pm 0.76$ & $2.77 \pm 0.14$ & $38.18 \pm 0.45$ & $1.54 \pm 0.17$ & $9.8 \pm 0.2$ & $47.85 \pm 7.76$ & $28.27 \pm 1.43$ & $20.32 \pm 4.59$ & $3.56 \pm 1.73$ \\
\hline $\mathrm{Si}_{3} \mathrm{~N}_{4 \mathrm{w}} / \mathrm{SiCN}-2$ & $56.4 \pm 0.63$ & $5.21 \pm 0.11$ & $36.58 \pm 0.43$ & $1.81 \pm 0.09$ & $19.0 \pm 0.1$ & $47.19 \pm 3.32$ & $27.42 \pm 0.58$ & $21.49 \pm 2.26$ & $3.90 \pm 0.47$ \\
\hline $\mathrm{Si}_{3} \mathrm{~N}_{4 \mathrm{w}} / \mathrm{SiCN}-3$ & $55.73 \pm 1.28$ & $6.23 \pm 0.33$ & $36.16 \pm 0.89$ & $1.88 \pm 0.06$ & $22.5 \pm 0.7$ & $45.98 \pm 5.69$ & $27.69 \pm 1.47$ & $22.52 \pm 3.96$ & $3.81 \pm 0.27$ \\
\hline $\mathrm{Si}_{3} \mathrm{~N}_{4 \mathrm{w}} / \mathrm{SiCN}-4$ & $55.65 \pm 0.8$ & $6.89 \pm 0.54$ & $35.53 \pm 0.15$ & $1.93 \pm 0.11$ & $25.2 \pm 0.6$ & $47.01 \pm 3.17$ & $27.34 \pm 2.14$ & $21.91 \pm 0.60$ & $3.74 \pm 0.44$ \\
\hline
\end{tabular}
respectively. Figure 4 shows the values of $x, y$, and $z$,

Table 3 Chemical composition of samples and calculated chemical composition of the SiCN matrix prepared by PIP

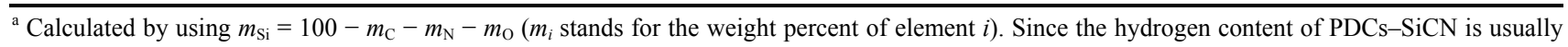
below $1 \mathrm{wt} \%$, the error introduced from this calculation is tolerable. However, the reliability of this calculation could be a concern for samples annealed at 900 and $1100{ }^{\circ} \mathrm{C}$ since they may contain relatively higher content of hydrogen residuals. 

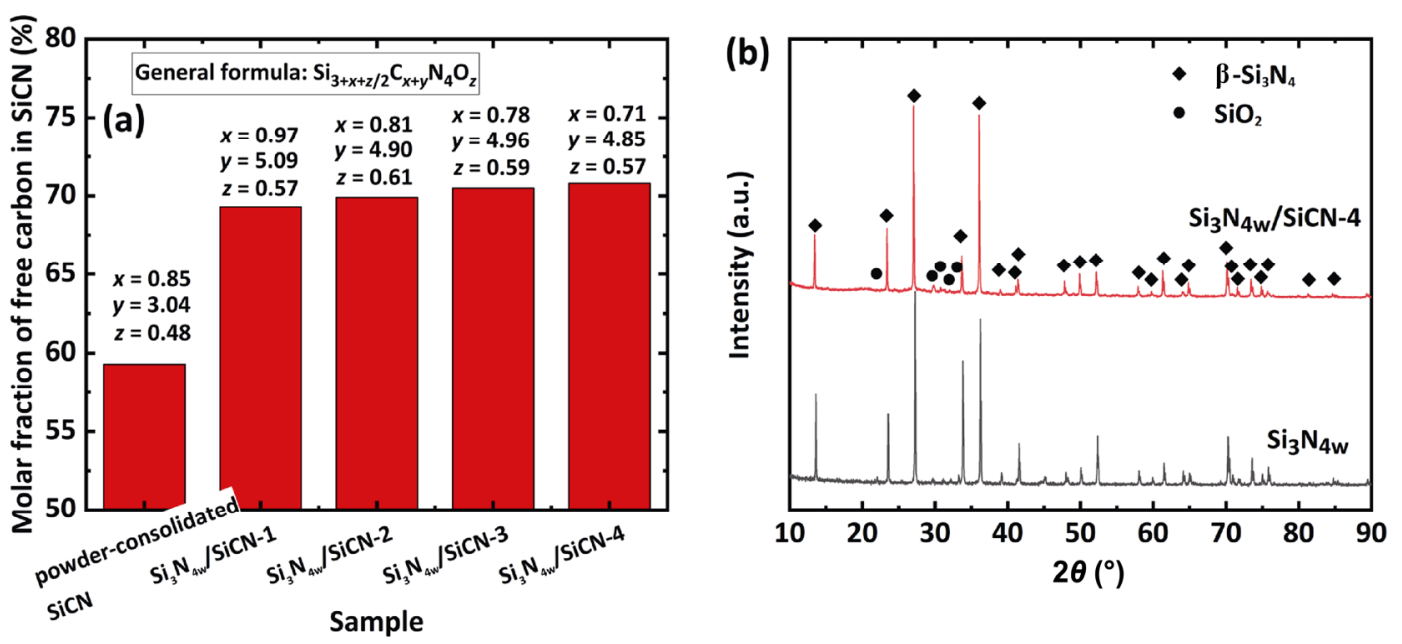

Fig. 4 (a) The values of $x, y$, and $z$, and the molar fraction of free carbon phase of SiCN prepared by both powder consolidation and PIP. (b) XRD of the $\mathrm{Si}_{3} \mathrm{~N}_{4 \mathrm{w}}$ and $\mathrm{Si}_{3} \mathrm{~N}_{4 \mathrm{w}} / \mathrm{SiCN}-4$.

and the molar fraction of free carbon phase of SiCN prepared by both powder consolidation and PIP. The values of $x$ and $z$ of SiCN matrix were close to that of the powder consolidated $\mathrm{SiCN}$, while the value of $y$ was $59.5 \%-67.4 \%$ higher, suggesting that higher content of $\mathrm{C}$ element in $\mathrm{SiCN}$ matrix led to a higher content of free carbon phase. Figure 4(b) shows the XRD patterns of $\mathrm{Si}_{3} \mathrm{~N}_{4 \mathrm{w}}$ and $\mathrm{Si}_{3} \mathrm{~N}_{4 \mathrm{w}} / \mathrm{SiCN}-4$. As can be seen, the $\mathrm{Si}_{3} \mathrm{~N}_{4 \mathrm{w}}$ sample was mainly composed of $\beta-\mathrm{Si}_{3} \mathrm{~N}_{4}$ and a small amount of $\mathrm{SiO}_{2}$ impurities. Special effort was carried out to examine whether diffraction peaks of graphitic carbon exist in the XRD pattern of the $\mathrm{Si}_{3} \mathrm{~N}_{4 \mathrm{w}} / \mathrm{SiCN}-4$ sample. However, The $\mathrm{Si}_{3} \mathrm{~N}_{4 \mathrm{w}} / \mathrm{SiCN}-4$ sample showed no extra diffraction peaks. It is probable that because of the amorphous nature of $\mathrm{Si}-\mathrm{C}-\mathrm{N}$ ceramic network and low content and crystallinity of free carbon in $\mathrm{SiCN}$ matrix, its diffraction feature was masked in the strong diffraction of $\beta-\mathrm{Si}_{3} \mathrm{~N}_{4}$.

The structure of free carbon was studied by Raman spectroscopy (Fig. 5). In Fig. 5(a), all spectra showed two peaks around 1350 and $1580 \mathrm{~cm}^{-1}$, corresponding to $\mathrm{D}$ band and $\mathrm{G}$ band, respectively, which is a typical character of the Raman spectrum of disordered carbon. According to studies on the phononic and electronic structure of carbon materials [37,38], the D peak is a breathing mode of $A_{1 \mathrm{~g}}$ symmetry which is forbidden in perfect graphite and only active in the presence of disorder. The intensity of $\mathrm{D}$ peak is therefore strictly connected to the presence of six-fold aromatic rings. The $G$ peak with $E_{2 \mathrm{~g}}$ symmetry, on the other hand, involves the in-plane bond-stretching motion of $\mathrm{sp}^{2}$ carbon atoms. Compared with that of powder-consolidated $\mathrm{SiCN}$, the D and G bands in the spectra of SiCN matrix were more separated from each other. Besides, two additional bands, the second order G' band around $2700 \mathrm{~cm}^{-1}$, which is the over tone of $\mathrm{D}$ band, and a band around $2900 \mathrm{~cm}^{-1}$, which is a combination mode of D + G, also appeared in the spectra of SiCN matrix. These differences in Raman spectra between SiCN materials pointed out that the structure of free carbon in them was different. More information on the structure of free carbon was obtained by quantitative analysis of these spectra. To do so, Gaussian curve fitting of Raman bands was performed in the range from 800 to $2000 \mathrm{~cm}^{-1}$. In order to get a better fitting, a minor peak (D" band around $1500 \mathrm{~cm}^{-1}$ ) was included in the fitting [39] when necessary. Peak position, full width at half maximum (FWHM), and the ratio of the integrated peak intensities of D and G band are shown in Table 3. The lateral size of carbon cluster can be estimated in Ref. [40]:

$$
\frac{I_{\mathrm{D}}}{I_{\mathrm{G}}}=C^{\prime}(\lambda) L_{\mathrm{a}}^{2}
$$

where $I_{\mathrm{D}}$ and $I_{\mathrm{G}}$ are the intensities of the $\mathrm{D}$ and $\mathrm{G}$ band, respectively. $C^{\prime}(\lambda)$ is a coefficient as a function of the wavelength of the incident laser. $C^{\prime}(532 \mathrm{~nm})=$ $0.0062 \AA^{-2} . L_{\mathrm{a}}$ is the lateral size of the carbon cluster. Equation (4) gives a good approximation when $L_{\mathrm{a}} \approx$ $2 \mathrm{~nm}[39,40]$. Data in Table 4 show that values of $L_{\mathrm{a}}$ in different $\mathrm{SiCN}$ samples were close. The position of $\mathrm{G}$ band $\left(\omega_{\mathrm{G}}\right)$ of $\mathrm{SiCN}$ matrix shifted to a higher wavenumber of $\sim 1600 \mathrm{~cm}^{-1}$ and the FWHM of the band $\left(\mathrm{FWHM}_{\mathrm{G}}\right)$ is smaller compared with that of powderconsolidated SiCN. According to Ferrari and Robertson [40], this means that free carbon in the $\mathrm{SiCN}$ matrix 

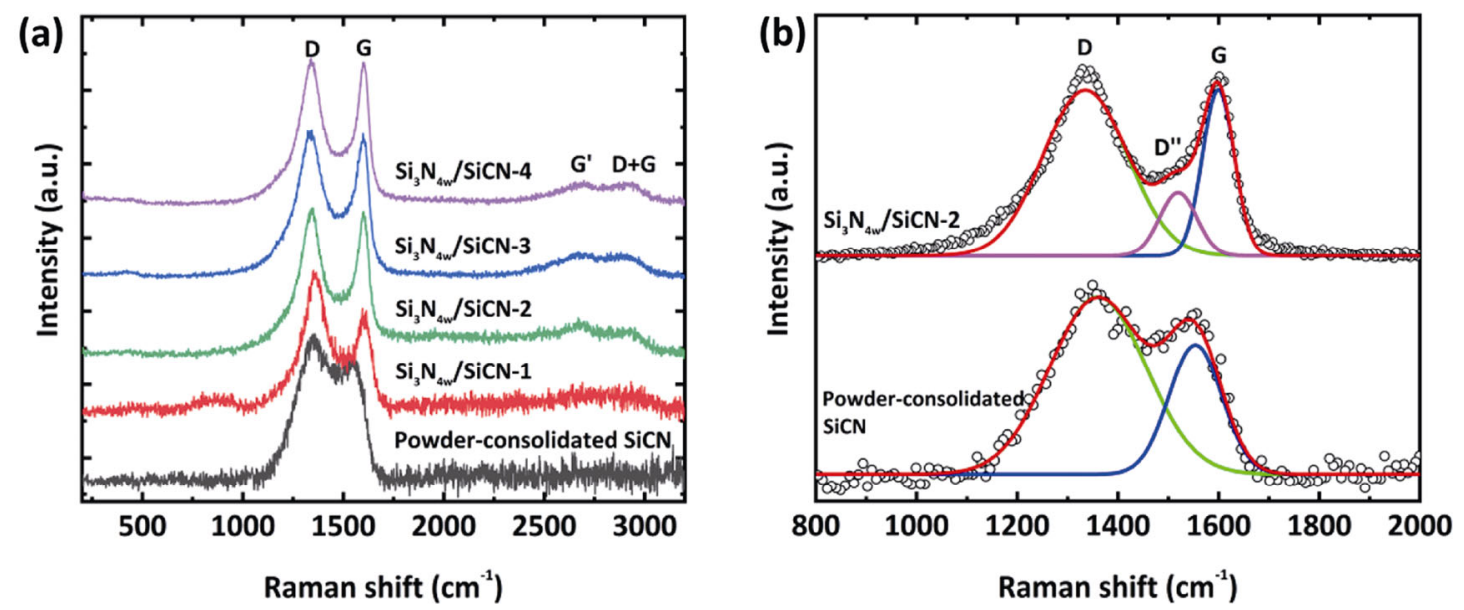

Fig. 5 (a) Raman spectra of powder consolidated $\mathrm{SiCN}$ and the composites. For the convenience of comparison, the intensities of the spectra were normalized. (b) Illustration of curve fitting of the spectra. The circles represent for the measured data and the solid lines are fitted curves.

Table 4 Peak position, FWHM, and intensity ratios of D and G band and calculated $L_{\mathbf{a}}$

\begin{tabular}{ccccccc}
\hline Sample & $\omega_{\mathrm{D}}\left(\mathrm{cm}^{-1}\right)$ & $\mathrm{FWHM}_{\mathrm{D}}\left(\mathrm{cm}^{-1}\right)$ & $\omega_{\mathrm{G}}\left(\mathrm{cm}^{-1}\right)$ & $\mathrm{FWHM}_{\mathrm{G}}\left(\mathrm{cm}^{-1}\right)$ & $I_{\mathrm{D}} / I_{\mathrm{G}}$ & $L_{\mathrm{a}}(\mathrm{nm})$ \\
\hline Powder-consolidated SiCN & 1360.4 & 225.8 & 1553.9 & 124.2 & 2.49 & 2.00 \\
$\mathrm{Si}_{3} \mathrm{~N}_{4 \mathrm{w}} / \mathrm{SiCN}-1$ & 1359.2 & 165.3 & 1604.7 & 81.8 & 2.76 & 2.11 \\
$\mathrm{Si}_{3} \mathrm{~N}_{4 \mathrm{w}} / \mathrm{SiCN}-2$ & 1335.3 & 197.6 & 1599.4 & 74.3 & 2.65 & 2.07 \\
$\mathrm{Si}_{3} \mathrm{~N}_{4 \mathrm{w}} / \mathrm{SiCN}-3$ & 1336.5 & 164.8 & 1601.2 & 70.2 & 2.38 & 1.96 \\
$\mathrm{Si}_{3} \mathrm{~N}_{4 \mathrm{w}} / \mathrm{SiCN}-4$ & 1336.7 & 162.3 & 1603.1 & 63.9 & 2.57 \\
\hline
\end{tabular}

was more ordered than that in powder-consolidated SiCN. Characteristics of Raman spectroscopy of SiCN matrix $\left(\omega_{\mathrm{G}} \approx 1600 \mathrm{~cm}^{-1}\right.$, smaller FWHM ${ }_{\mathrm{G}}$ compared with that of powder-consolidated $\mathrm{SiCN}$, the appearance of G' band) suggested that nanocrystalline graphite existed [40].

TEM analysis was performed on $\mathrm{Si}_{3} \mathrm{~N}_{4 \mathrm{w}} / \mathrm{SiCN}-2$ to reveal the detailed information of microstructure of the composites. Figure 6(a) shows an aggregate of rod-like $\mathrm{Si}_{3} \mathrm{~N}_{4 \mathrm{w}}$ and $\mathrm{SiCN}$ matrix. The HRTEM of 3 regions in Fig. 6(a) are presented in Figs. 6(b)-6(d). In Fig. 6(b), the interplanar spacing of the lattice was $6.62 \AA$, corresponding to the (001) plane of $\beta-\mathrm{Si}_{3} \mathrm{~N}_{4}$, showing the alignment of this crystal plane along the whisker axis. Figures 6(c) and 6(d) confirm the existence of nanocrystalline graphite. In Fig. 6(c), the interplanar spacing of carbon layers (3.44 $\AA$ ) was very close to that of ideal graphite crystal. To our knowledge, this well-developed graphite structure was rarely found in PDCs pyrolyzed below $1500{ }^{\circ} \mathrm{C}$ [12,15,41,42]. In Fig. 6(d) the free carbon shows a turbostratic feature. Nanocrystalline graphites with these two kinds of nano-morphology were both frequently observed in the sample. In contrast, our previously study [25] revealed that powder-consolidated $\mathrm{SiCN}$ showed a highly amorphous nature in which no crystalline carbon could be found. Taken together, chemical analysis, Raman spectroscopy, and TEM results proved that the microstructure of powder-consolidated $\mathrm{SiCN}$ and that of SiCN matrix differed in both the amount and structure of free carbon. SiCN matrix possessed a higher concentration of free carbon. Besides, nanocrystalline graphite existed in SiCN matrix.

There could be a concern that the high graphitization degree of free carbon in $\mathrm{SiCN}$ matrix was a consequence of long-term heat-treatment at $900{ }^{\circ} \mathrm{C}$ due to the repeated PIP cycles, rather than the result of a different carbonization mechanism. To rule out this possibility, powder-consolidated $\mathrm{SiCN}$ was heat-treated at $900{ }^{\circ} \mathrm{C}$ in $\mathrm{N}_{2}$ atmosphere for $10 \mathrm{~h}$ and then characterized by Raman and dielectric spectroscopy. Figure 7 shows that both Raman spectroscopy and dielectric properties were almost unchanged after the heat-treatment, which proved that structure of free carbon of SiCN was stable during the repeated PIP cycles.

The fact that, graphitization degree of carbon in SiCNs prepared by PIP or pyrolyzed from a fully dense precursor green bodies was higher than that of powder-consolidated SiCN, was also discovered by the 

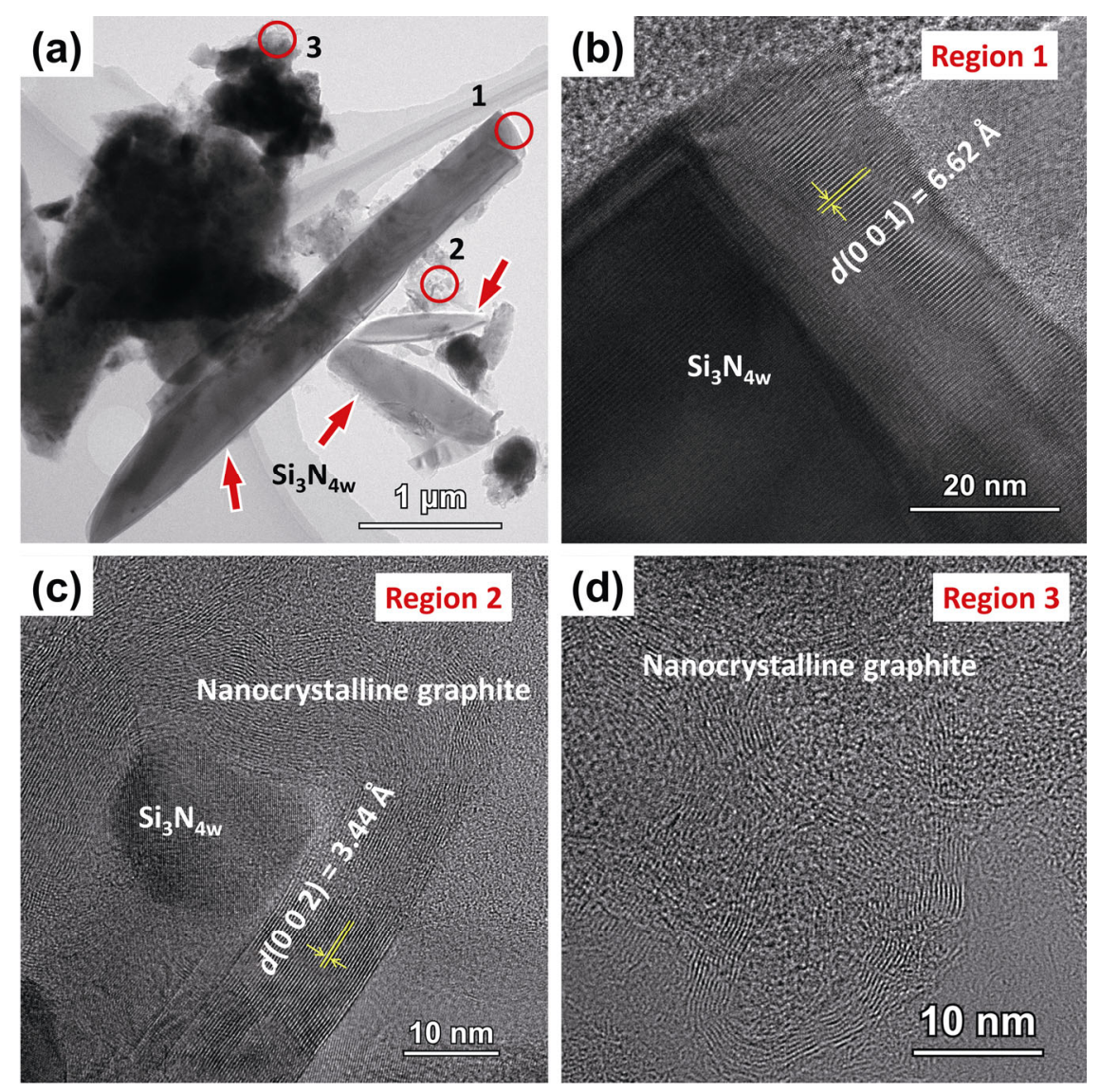

Fig. 6 TEM micrographs of $\mathrm{Si}_{3} \mathrm{~N}_{4 \mathrm{w}} / \mathrm{SiCN}-2$. (a) An aggregate of rod-like $\mathrm{Si}_{3} \mathrm{~N}_{4 \mathrm{w}}$ and $\mathrm{SiCN}$ matrix. (b) HRTEM of region 1 highlighted in (a) showing the (001) lattice image of $\mathrm{Si}_{3} \mathrm{~N}_{4 \mathrm{w}}$. (c, d) HRTEM of regions 2 and 3, respectively, showing the structure of nanocrystalline graphite.
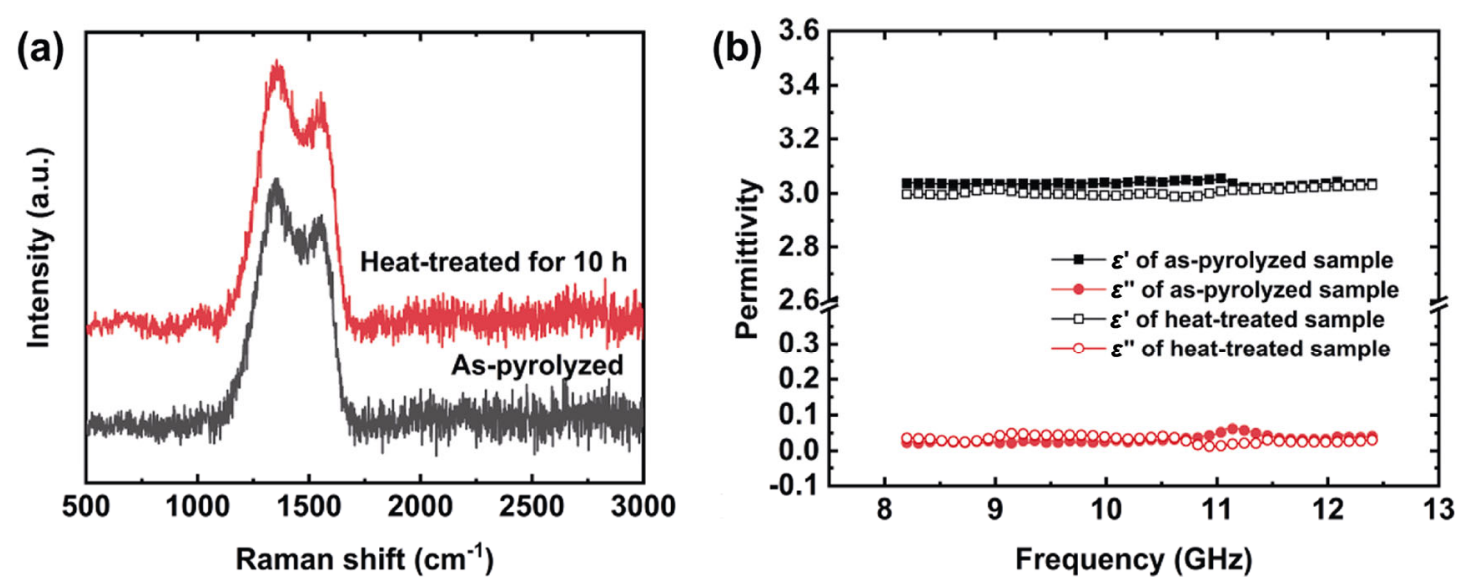

Fig. 7 (a) Raman spectroscopy and (b) dielectric spectroscopy of powder-consolidated SiCN before and after heat-treatment at $900{ }^{\circ} \mathrm{C}$ in $\mathrm{N}_{2}$ atmosphere for $10 \mathrm{~h}$.

study of Gregori et al. [42], Gao et al. [43], and Ma et al. [44], suggesting that the influence of pore-structure on the structure of carbon was a common issue in $\mathrm{SiCN}$. However, the mechanism, which is the main purpose of this article to undiscover, was not clearly discussed by previous study.

\section{2 Dielectric properties of $\mathrm{Si}_{3} \mathrm{~N}_{4 w} / \mathrm{SiCN}$}

Evolution of dielectric properties during the densification process was monitored by testing the complex permittivity of samples prepared by different PIP cycles (Fig. 8). The whisker preform exhibits a low 
permittivity and a low loss $\left(\tan \delta=\varepsilon_{\mathrm{r}}^{\prime \prime} / \varepsilon_{\mathrm{r}}^{\prime}\right)$ nature with the average value of $\varepsilon_{\mathrm{r}}^{\prime}$ and $\tan \delta$ over X band being 3.2 and $5.6 \times 10^{-3}$, respectively. Our previous study along with the literature has demonstrated that powderconsolidated SiCNs pyrolyzed from polysilazane below $1500{ }^{\circ} \mathrm{C}$ also possess this low permittivity-low loss property owing to their amorphous nature (average $\varepsilon_{\mathrm{r}}^{\prime}$ and $\tan \delta$ over $\mathrm{X}$ band being 3.0 and $3.0 \times 10^{-2}$, respectively, for $\mathrm{SiCN}$ pyrolyzed at $900{ }^{\circ} \mathrm{C}$ [25]). According to the theory of dielectrics, for non-magnetic materials complex permittivity describes their interactions with the electromagnetic field. More specifically, the real part, $\varepsilon_{\mathrm{r}}^{\prime}$, is a measure of ability to store the energy by polarization, while the imaginary part, $\varepsilon_{\mathrm{r}}^{\prime \prime}$, the ability to dissipate energy by electric conduction or dielectric relaxation. For a sinusoidal electric field, it can be derived that [45]:

$$
\begin{gathered}
P_{1}=\frac{1}{2} \varepsilon_{0} \varepsilon_{\mathrm{r}}^{\prime} E_{0}^{2} \\
P_{2}=\frac{1}{2} \sigma E_{0}^{2}=\frac{1}{2} \omega \varepsilon_{0} \varepsilon_{\mathrm{r}}^{\prime \prime} E_{0}^{2}
\end{gathered}
$$
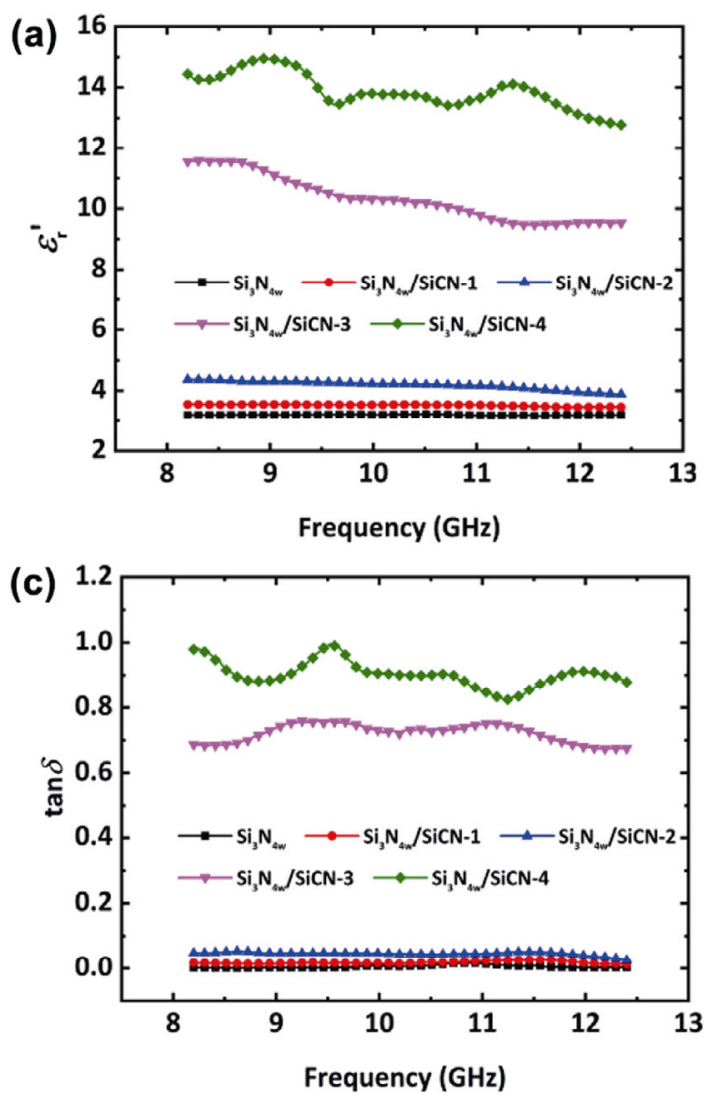

among which $P_{1}$ and $P_{2}$ are the average power of energy stored and dissipated per unit volume, respectively, $\sigma$ is the dielectric conduction, $\varepsilon_{0}$ is the dielectric constant of vacuum, and $E_{0}$ is the amplitude of the electric field strength. It would be reasonable to infer that the dielectric properties of the $\mathrm{Si}_{3} \mathrm{~N}_{4 \mathrm{w}} / \mathrm{SiCN}$ composites show similar features with that of their components, since the combination of two dielectrics with low polarizability $\left(\varepsilon_{\mathrm{r}}^{\prime}\right)$ and weak energy consuming ability $\left(\varepsilon_{\mathrm{r}}^{\prime \prime}\right)$ would naturally yield a composite with poor ability to interact with the electromagnetic wave.

During the first two PIP cycles, the composite witnessed mild increase in the real and imaginary parts of permittivity and the dielectric loss. However, unexpected drastic increase in both $\varepsilon_{\mathrm{r}}^{\prime}$ and $\varepsilon_{\mathrm{r}}^{\prime \prime}$ occurred when the number of PIP cycle increased from 2 to 3 . After 3 PIP cycles, with a porosity of $32.2 \%$, the $\varepsilon_{\mathrm{r}}^{\prime}$ and $\varepsilon_{\mathrm{r}}^{\prime \prime}$ of composites increased to 10.3 and 7.45. The rapid increase in $\varepsilon_{\mathrm{r}}^{\prime}$ and $\varepsilon_{\mathrm{r}}^{\prime \prime}$ continued in the following PIP process.

Understanding this unexpected change in dielectric properties demands a deep insight into the microstructural
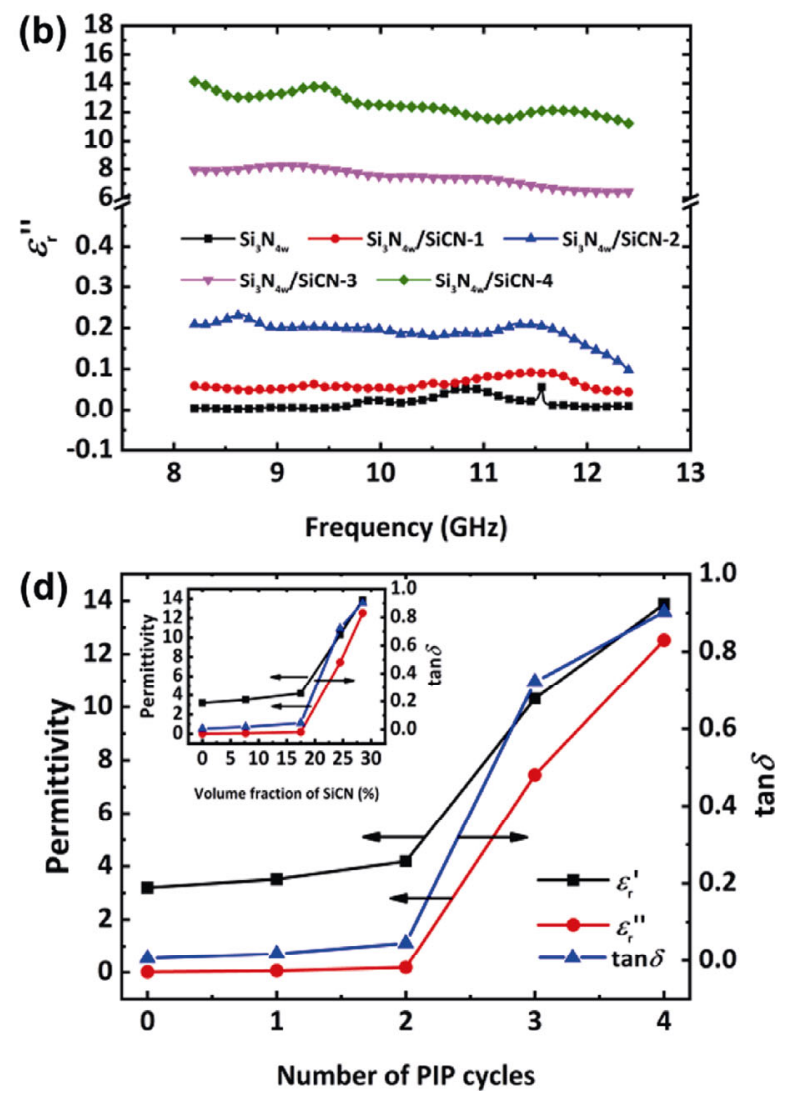

Fig. 8 Dielectric properties of $\mathrm{Si}_{3} \mathrm{~N}_{4 \mathrm{w}}$ preform and the composites prepared by different PIP cycles. (a) $\varepsilon_{\mathrm{r}}^{\prime}$. (b) $\varepsilon_{\mathrm{r}}^{\prime \prime}$. (c) tan $\delta$. (d) Average $\varepsilon_{\mathrm{r}}^{\prime}, \varepsilon_{\mathrm{r}}^{\prime \prime}$, and tan $\delta$ over X band as a function of the number of PIP cycles and the volume fraction of SiCN matrix (the inset). 
evolution of composites during PIP process and the dielectric behavior in this $\mathrm{Si}_{3} \mathrm{~N}_{4 \mathrm{w}} / \mathrm{SiCN}$ system, which will be discussed in the following sections.

\section{3 Evolution mechanisms of microstructure and dielectric properties}

Dielectric properties of a mixture consisting of two or more dielectric phases with different dielectric properties have attracted much attention ever since the establishment of the theory of dielectrics. Due to field distortions inside the mixture caused by pilling up of space charges at the interfaces, the mixture shows an effective permittivity $\left(\varepsilon_{\text {eff }}\right)$ for an outside observer which can be predicted by a logarithmic mixing rule given by Lichtenecker [46]:

$$
\left(\varepsilon_{\mathrm{eff}}^{\prime}\right)^{n}=\sum_{i} v_{i}\left(\varepsilon_{i}^{\prime}\right)^{n}, \quad\left(\varepsilon_{\mathrm{eff}}^{\prime \prime}\right)^{n}=\sum_{i} v_{i}\left(\varepsilon_{i}^{\prime \prime}\right)^{n}
$$

where $\varepsilon_{i}^{\prime}$ and $\varepsilon_{i}^{\prime \prime}$ are real and imaginary parts of the permittivity of phase $i$, respectively. $n$ is a geometric factor ranging from -1 to 1 . This mixing rule can be easily understood by examining the capacitance of a condenser with a multilayered dielectric filled between its electrodes (Fig. 9). When the layers are perpendicular to the applied electric field (Fig. 9(a)), the structure can be treated as a circuit composed of condensers in series. Then $\varepsilon_{\text {eff }}$ can be derived based on constant electric flux density of each layer:

$$
\frac{1}{\varepsilon_{\mathrm{eff}}^{\prime}}=\sum_{i} \frac{v_{i}}{\varepsilon_{i}^{\prime}}, \frac{1}{\varepsilon_{\mathrm{eff}}^{\prime \prime}}=\sum_{i} \frac{v_{i}}{\varepsilon_{i}^{\prime \prime}}
$$
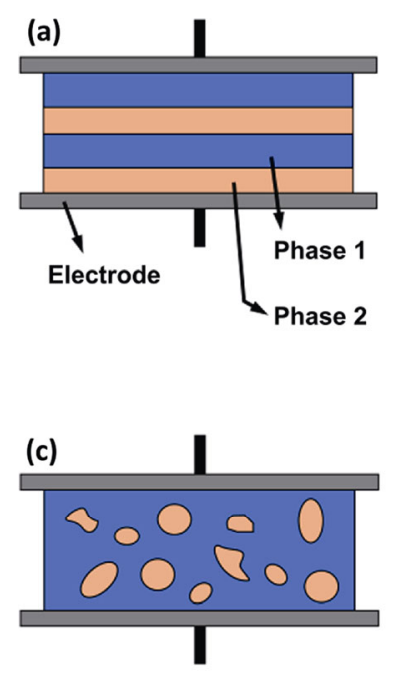

When the layers are arranged in the same direction with the applied electric field (Fig. 9(b)), the structure becomes a parallel circuit. Based on constant electric field strength in each layer, the $\varepsilon_{\text {eff }}$ can be derived as

$$
\varepsilon_{\mathrm{eff}}^{\prime}=\sum_{i} v_{i} \varepsilon_{i}^{\prime}, \quad \varepsilon_{\mathrm{eff}}^{\prime \prime}=\sum_{i} v_{i} \varepsilon_{i}^{\prime \prime}
$$

Equations (8) and (9) are obviously two extremes for Eq. (7) with $n=-1$ and 1, respectively, and they correspond to the upper and lower limit of $\varepsilon_{\text {eff }}$ of dielectric mixtures. For a composite material containing dispersing particles (Fig. 9(c)) with various states of distribution, concentration, and geometry, its $\varepsilon_{\text {eff }}$ can be described by choosing an appropriate $n$ (Fig. 9(d)). Considering a mixture of spherical particles embedded in a matrix, Maxwell derived the following relationship [46]:

$$
\varepsilon_{\mathrm{eff}}^{\prime}=\frac{v_{1} \varepsilon_{1}^{\prime}\left(\frac{2}{3}+\frac{\varepsilon_{2}^{\prime}}{3 \varepsilon_{1}^{\prime}}\right)+v_{2} \varepsilon_{2}^{\prime}}{v_{1}\left(\frac{2}{3}+\frac{\varepsilon_{2}^{\prime}}{3 \varepsilon_{1}^{\prime}}\right)+v_{2}}
$$

When the embedded particle has a higher dielectric constant than the matrix, results of Eq. (10) are quite close to that of the logarithmic mixing rule (Fig. 9(d)). For materials with low dielectric loss, this mixing rule agreed well with many experimental measurements [46], showing that the effective permittivity is just an average of that of each components of the mixture. When the inclusions are high-lossy (for example, conductive phases), a very non-linear phenomenon
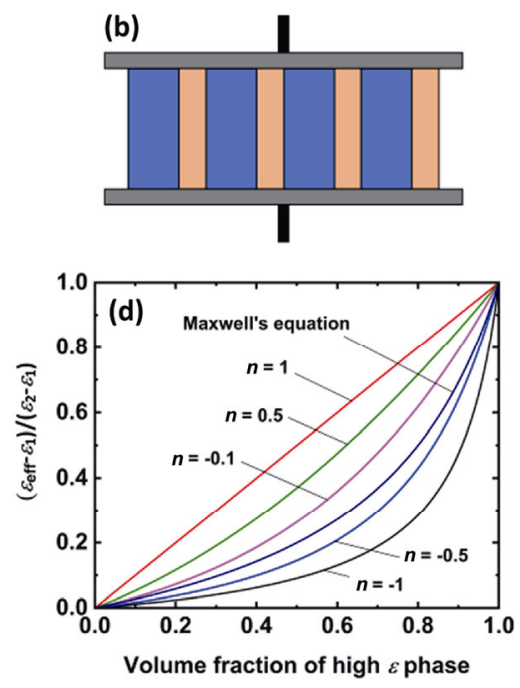

Fig. 9 Condensers filled with composite dielectric materials with different phase distribution: (a) layers perpendicular to the electric field, (b) layers parallel to the electric field, and (c) particulate phase 2 dispersed randomly. (d) Real or imaginary part of effective permittivity as a function of volume fraction of high $\varepsilon$ phase. 
called dielectric percolation happens when the concentration of the inclusions reaches a threshold, i.e., a very abrupt change in the dielectric behavior takes place. Due to the interactions between the high-lossy inclusions, the dielectric constant can be higher than any of that of the components [47-49].

To examine the effect of phase composition on dielectric properties of the $\mathrm{Si}_{3} \mathrm{~N}_{4 \mathrm{w}} / \mathrm{SiCN}$, complex permittivity of materials with different compositions was measured, and the results were summarized in Fig. 10. The abrupt surges in real and imaginary parts of permittivity were only observed in $\mathrm{Si}_{3} \mathrm{~N}_{4 \mathrm{w}} / \mathrm{SiCN}$ when concentration of SiCN matrix prepared by PIP reached $24.5 \mathrm{vol} \%$. This dielectric percolation suggests that unlike powder-consolidated $\mathrm{SiCN}, \mathrm{SiCN}$ matrix prepared by PIP is a highly-lossy component. Higher concentration and graphitization degree of free carbon in $\mathrm{SiCN}$ were considered to account for this high dielectric loss. In order to confirm the role of free carbon, $\mathrm{Si}_{3} \mathrm{~N}_{4 \mathrm{w}} / \mathrm{SiCN}-4$ was subjected to oxidation at $600{ }^{\circ} \mathrm{C}$ in static air and the dielectric properties of the composites were measured after different oxidation time. Figures 11(a) and 11(b) show that only after $2 \mathrm{~h}$ of oxidation, both $\varepsilon_{\mathrm{r}}^{\prime}$ and $\varepsilon_{\mathrm{r}}^{\prime \prime}$ dropped dramatically. When oxidation time increased from 2 to $4 \mathrm{~h}, \varepsilon_{\mathrm{r}}^{\prime}$ and $\varepsilon_{\mathrm{r}}^{\prime \prime}$ continued to decrease mildly. After $4 \mathrm{~h}, \varepsilon_{\mathrm{r}}^{\prime}$ and $\varepsilon_{\mathrm{r}}^{\prime \prime}$ were relatively stable with the increase of oxidation time. $\varepsilon_{\mathrm{r}}^{\prime}$ and $\varepsilon_{\mathrm{r}}^{\prime \prime}$ of $\mathrm{Si}_{3} \mathrm{~N}_{4 \mathrm{w}} / \mathrm{SiCN}-4$ after $10 \mathrm{~h}$ of oxidation were comparable to those of $\mathrm{Si}_{3} \mathrm{~N}_{4}$ ceramic and powder-consolidated $\mathrm{SiCN}$ with the same porosity $\left(\varepsilon_{\mathrm{r}}^{\prime} \approx 3.0, \varepsilon_{\mathrm{r}}^{\prime \prime} \approx 0.03\right)$. As has proved by our previous study [25], oxidation at $600{ }^{\circ} \mathrm{C}$ causes the depletion of free carbon phase while $\mathrm{SiC}$ and $\mathrm{Si}_{3} \mathrm{~N}_{4}$

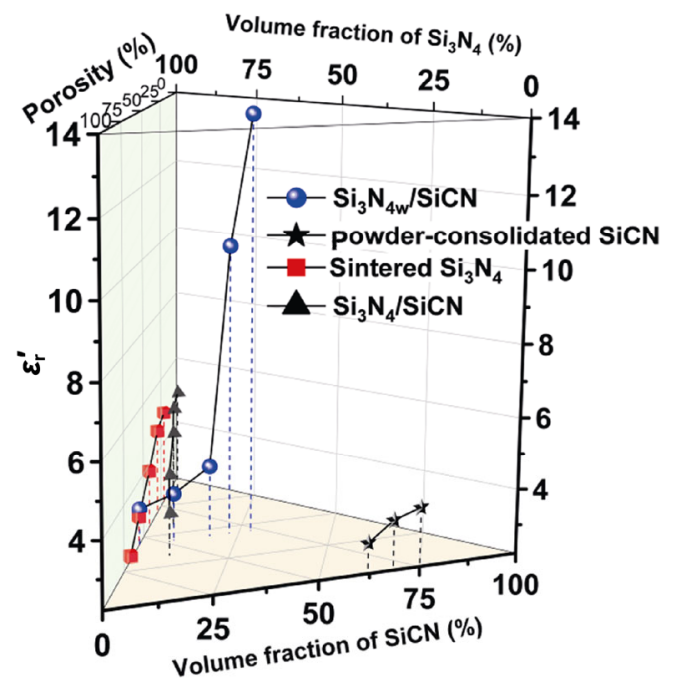

Fig. 10 Real part of permittivity of sintered porous $\mathrm{Si}_{3} \mathrm{~N}_{4}$, powder-consolidated $\mathrm{SiCN}$, and $\mathrm{Si}_{3} \mathrm{~N}_{4 \mathrm{w}} / \mathrm{SiCN}$ composites.
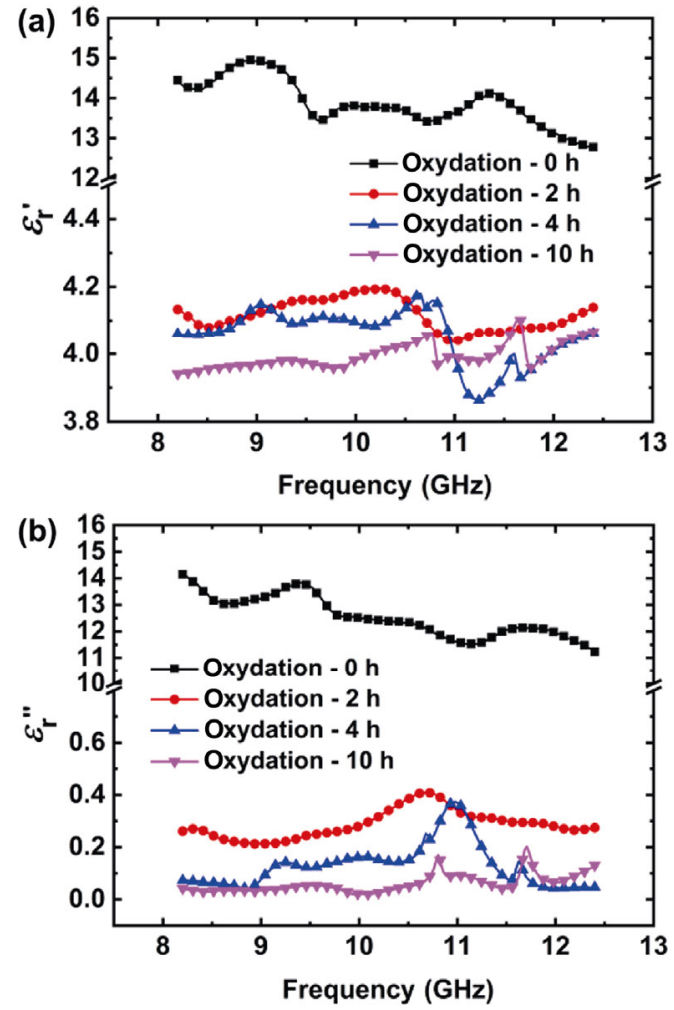

Fig. 11 (a) Real and (b) imaginary parts of permittivity of $\mathrm{Si}_{3} \mathrm{~N}_{4 \mathrm{w}} / \mathrm{SiCN}-4$ after $0,2,4$, and $10 \mathrm{~h}$ of oxidation at $600{ }^{\circ} \mathrm{C}$ in static air.

( $\mathrm{Si}-\mathrm{C}-\mathrm{N}$ network) have a good oxidation resistance at $600{ }^{\circ} \mathrm{C}$. Combined with fact that in Fig. 10, when the porosity of $\mathrm{Si}_{3} \mathrm{~N}_{4 \mathrm{w}} / \mathrm{SiCN}-n$ samples was close to, but higher than, that powder-consolidated $\mathrm{SiCN}$, their dielectric constant was higher, especially for $\mathrm{Si}_{3} \mathrm{~N}_{4 \mathrm{w}} /$ SiCN-3 and $\mathrm{Si}_{3} \mathrm{~N}_{4 \mathrm{w}} / \mathrm{SiCN}-4$. It can be concluded that high $\varepsilon_{\mathrm{r}}^{\prime}$ and $\varepsilon_{\mathrm{r}}^{\prime \prime}$ were owing to nanocrystalline graphite in $\mathrm{SiCN}$ matrix.

Finally, the formation mechanism of nanocrystalline graphite in SiCN matrix (Fig. 12) and its effect on the dielectric properties of the $\mathrm{Si}_{3} \mathrm{~N}_{4 \mathrm{w}} / \mathrm{SiCN}$ composite can be explained as follows: Formula of PSZ precursor used in this study can be written as $\mathrm{Si}_{4} \mathrm{C}_{8} \mathrm{~N}_{4} \mathrm{H}_{6}$ according to its formal composition. The pyrolysis process of PSZ precursor yielding a $\mathrm{SiCN}$ ceramic can be expressed by the following equation:

$$
\mathrm{Si}_{4} \mathrm{C}_{8} \mathrm{~N}_{4} \mathrm{H}_{6} \rightarrow \mathrm{Si}_{3+x} \mathrm{C}_{x+y} \mathrm{~N}_{4}+m \mathrm{CH}_{n}(\mathrm{~g})+p \mathrm{H}_{2}(\mathrm{~g})
$$

where $x$ and $y$ are the molar quantities of $\mathrm{SiC}$ and free carbon phase, respectively, and $m, n$, and $p$ are the stoichiometric numbers in the equation. Assuming that hydrocarbon species $\left(\mathrm{CH}_{n}\right)$ and hydrogen were the only escaped volatile species and all $\mathrm{Si}$ and $\mathrm{N}$ atoms forming the backbone of the precursor molecule were 


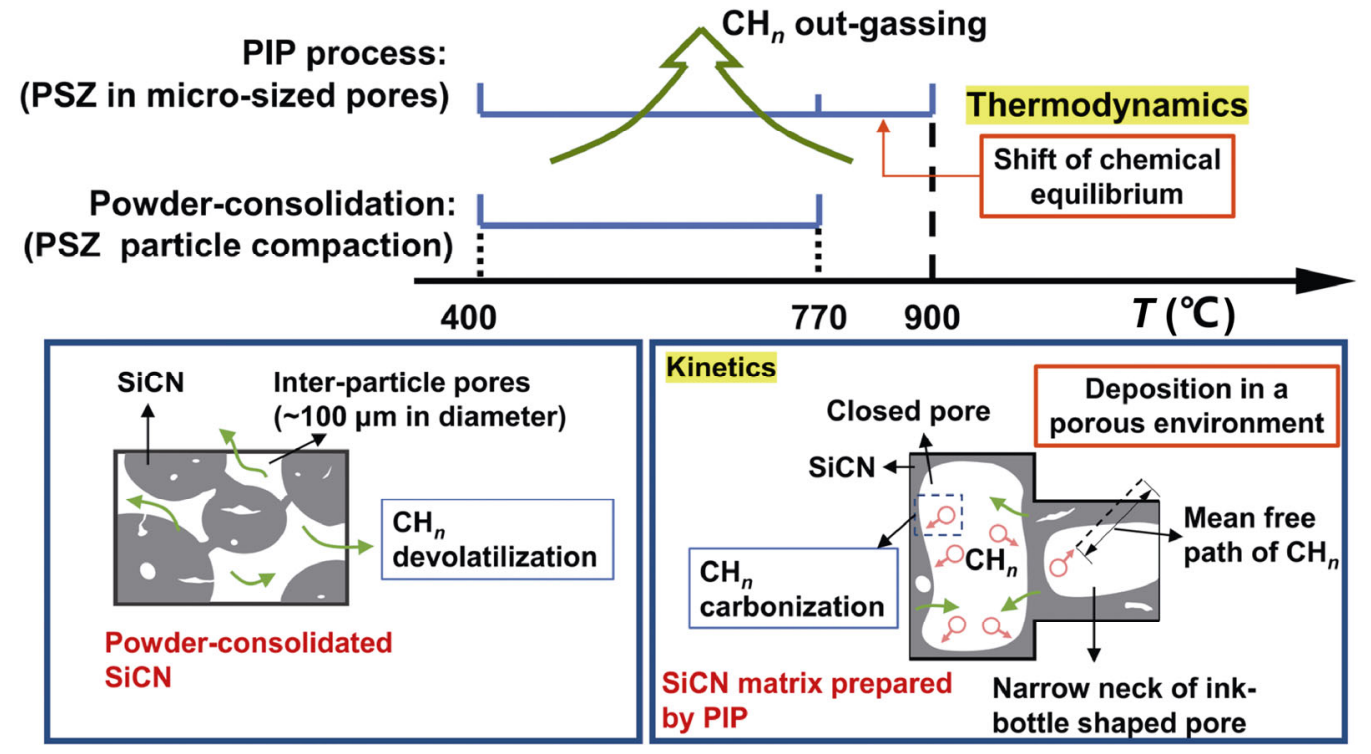

Fig. 12 Illustration of formation mechanism of nanocrystalline graphite in SiCN matrix.

consolidated into SiCN ceramic during pyrolysis, it can be solved that $x=1$ and $y+m=7$. $x$ values reported in Fig. 4 were slightly smaller than 1 due to the existence of oxygen in samples. Upon pyrolysis, part of the carbon atoms ( 1 out of 8 ) in the precursor forms $\mathrm{Si}-\mathrm{C}$ bond with silicon and the others either form free carbon phase or leave the system as $\mathrm{CH}_{n}$. Then the value of $y / 7$ is the yield of the transformation from hydrocarbon groups in PSZ molecule to free carbon phase in SiCN ceramic. $y$ values reported in Fig. 4 show that for powder consolidation process, the yield was $43.4 \%$. For PIP process, the yield was significantly higher $(69.3 \%-71.4 \%)$. Another feature of free carbon in $\mathrm{SiCN}$ is that PIP process produces carbon with higher graphitization degree. The above mentioned two features suggest that carbonization mechanism in PIP differs from that of powder consolidation process. In our opinion, the difference in carbon content and structure can be attributed to the pore-structure of samples. According to study, during the pyrolysis of hydrocarbons, a higher carbon yield and higher graphitization degree of product can be realized by the so-called pressure carbonization, i.e., when the carbonization is performed under pressure, gaseous decomposition products can be carbonized to give solid carbon. In addition, the structure of the resultant carbon differs from that obtained in a normal or reduced pressure due to thermodynamic and kinetic factors $[18,50]$. The pressure carbonization can be realized by applying external compression or by build-up of pressure due to gas formation in a closed vessel. In our case, as has been demonstrated by mercury porosimetry, powder-consolidated $\mathrm{SiCN}$ was featured with large inter-particle pores which were beneficial for devolatilization, while the pores inside the whisker preform were connected to the surface through narrow necks with submicron-sized diameters. During the PIP process, enrichment of precursor and pyrolysis product inside small pores occurred due to capillary force, resulting in the decrease of gas permeability and even the closure of some of the pores. When the diffusion channels for gaseous decomposition products were blocked in some micro area by this mechanism, closed vessels for pressure carbonization formed. In fact, the build-up of internal pressure during carbonization is a major issue in coking industry [51]. Due to the blocking of micropores by a plastic coal layer with low gas permeability, the coking pressure inside the plastic layer arises, which plays a key role in the change of macro-molecular structure and devolatilization characteristics during carbonization [52]. Consider the thermodynamics of the pyrolysis reaction expressed by Eq. (11). Le Chatelier's principle states that a system at equilibrium, when subjected to a disturbance, responds in a way that tends to minimize the effect of the disturbance. This implies that, if the pressure of a system at equilibrium increased, then the reaction will adjust so as to minimize the increase in pressure. This can be realized by reducing the number of particles in the gas phase [53]. This means that under an elevated pressure, the progress of pyrolysis (Eq. (11)) can be suppressed due to the shift of 
equilibrium. Pyrolysis can only take place at a higher temperature so that more energy is supplied to activate the pyrolysis process. In Fig. 1(b), the out-gassing of hydrocarbons continued up to $900{ }^{\circ} \mathrm{C}$, which agrees with our thermodynamic analysis. The hydrocarbon out-gassing at an elevated temperature was beneficial for carbon deposition because at low temperatures, deposition is limited by chemical reaction, and increase of temperature effectively enhances the rate of deposition [30].

The microstructure of whisker preform also promotes the deposition of carbon due to kinetic factors. First, since the hydrocarbons diffused through submicronsized channels within the whisker preforms, the mean-free-paths $(\lambda)$ of hydrocarbon molecules were of interest because this parameter controls the diffusion process. According to molecular dynamics, $\lambda$ depends on the temperature $(T)$, pressure $(P)$ as well as the molecular diameter $(d)$ [53]:

$$
\lambda=\frac{k T}{\sqrt{2} \pi d^{2} P}
$$

where $k$ is the Boltzmann constant. A rough estimation of $\lambda$ can be done by setting $T, d$, and $P$ to $800{ }^{\circ} \mathrm{C}$, $0.3 \mathrm{~nm}$, and $0.1 \mathrm{MPa}$, respectively. The result of the estimation $(\lambda=0.37 \mu \mathrm{m})$ showed that $\lambda$ was comparable to the diameter of the pores in the whisker preform and composites. This means that high frequency of collision with pore wall happened which will increase the chance of heterogeneous nucleation and deposition of carbon. Second, the porous nature of the whisker preform and the composites has higher surface area, providing more active sites for the deposition process [54].

High concentration of free carbon and good conductivity of the nanocrystalline graphite make SiCN matrix prepared by PIP a highly-lossy phase. When its volume reached the percolation threshold, $\mathrm{Si}_{3} \mathrm{~N}_{4 \mathrm{w}} / \mathrm{SiCN}$ composites showed enhanced dielectric properties.

This study demonstrated the strong effect of porestructure on the microstructure and dielectric properties of PIP fabricated composites. During densification, pore-structure undergoes changes with the increase of numbers of PIP cycle, which could bring variation of microstructure between matrix materials prepared in different "pore environment". Since PIP is widely applied in the preparation of ceramic matrix composites, the issue highlighted in this paper could be a general concern for various material systems.

\section{Conclusions}

Microstructure and dielectric properties of PDC-SiCN prepared by PIP process in $\mathrm{Si}_{3} \mathrm{~N}_{4 \mathrm{w}}$ preforms were compared with its analogous powder-consolidated samples. Differences in both content and structure of free carbon between these two kinds of $\mathrm{SiCNs}$ pyrolyzed at $900{ }^{\circ} \mathrm{C}$ were highlighted. The results can be summarized as follows:

1) The release of $\mathrm{CH}_{n}$ and $\mathrm{H}_{2}$ during pyrolysis occurred for both PSZ powder and that inside the $\mathrm{Si}_{3} \mathrm{~N}_{4 \mathrm{w}}$ preforms. However, out-gassing of $\mathrm{CH}_{n}$ from PSZ completed at $770{ }^{\circ} \mathrm{C}$ for powder sample, while it continued up to $900{ }^{\circ} \mathrm{C}$ for $\mathrm{PSZ}$ in $\mathrm{Si}_{3} \mathrm{~N}_{4 \mathrm{w}}$ preform.

2) Pore size of $\mathrm{Si}_{3} \mathrm{~N}_{4 \mathrm{w}}$ preforms ranged from 40 to $680 \mathrm{~nm}$. During PIP, and these pores were gradually filled by SiCN matrix. Due to capillary effect, small pores were filled more quickly than large pores.

3) Content and graphitization degree of free carbon in $\mathrm{SiCN}$ matrix were higher than that in powderconsolidated SiCN. Besides, nanocrystalline graphite can be found in SiCN matrix while free carbon in powder-consolidated $\mathrm{SiCN}$ was amorphous.

4) $\varepsilon_{\mathrm{r}}^{\prime}$ and $\varepsilon_{\mathrm{r}}^{\prime \prime}$ of $\mathrm{Si}_{3} \mathrm{~N}_{4 \mathrm{w}} / \mathrm{SiCN}$ increased with the volume fraction of $\mathrm{SiCN}$ matrix. When volume fraction of $\mathrm{SiCN}$ matrix reached $17.5 \%-24.5 \%$, dielectric percolation happened, and the dielectric properties of the composite were greatly enhanced due to the highly-lossy nature of SiCN matrix.

5) Formation of nanocrystalline graphite in $\mathrm{SiCN}$ and high carbon yield of PIP process were attributed to the pore-structure of $\mathrm{Si}_{3} \mathrm{~N}_{4 \mathrm{w}}$ preform. Owing to low gas permeability caused by blocking of micro-sized pore in PIP process, $\mathrm{CH}_{n}$ released during pyrolysis reconsolidated into carbon through gas-state carbonization.

\section{Acknowledgements}

This work is supported by the National Natural Science Foundation of China (Grant Nos. 51632007, 51872229, and 52072304) and National Science and Technology Major Project (Grant No. 2017-VI-0007-0077). We would like to thank the Analytical \& Testing Center of Northwestern Polytechnical University for the kind assistance with electron microscopic characterization in this work. 


\section{References}

[1] Colombo P, Mera G, Riedel R, et al. Polymer-derived ceramics: 40 years of research and innovation in advanced ceramics. J Am Ceram Soc 2010, 93: 1805-1837

[2] Larson NM, Zok FW. In-situ 3D visualization of composite microstructure during polymer-to-ceramic conversion. Acta Mater 2018, 144: 579-589.

[3] Kotani M, Inoue T, Kohyama A, et al. Effect of SiC particle dispersion on microstructure and mechanical properties of polymer-derived SiC/SiC composite. Mater Sci Eng: A 2003, 357: 376-385.

[4] Mera G, Navrotsky A, Sen S, et al. Polymer-derived SiCN and SiOC ceramics-Structure and energetics at the nanoscale. J Mater Chem A 2013, 1: 3826.

[5] Galusek D, Reschke S, Riedel R, et al. In-situ carbon content adjustment in polysilazane derived amorphous $\mathrm{SiCN}$ bulk ceramics. J Eur Ceram Soc 1999, 19: 1911-1921.

[6] Haluschka C, Kleebe HJ, Franke R, et al. Silicon carbonitride ceramics derived from polysilazanes Part I. Investigation of compositional and structural properties. $J$ Eur Ceram Soc 2000, 20: 1355-1364.

[7] An L, Riedel R, Konetschny C, et al. Newtonian viscosity of amorphous silicon carbonitride at high temperature. $J$ Am Ceram Soc 1998, 81: 1349-1352.

[8] Riedel R, Ruswisch LM, An L, et al. Amorphous silicoboron carbonitride ceramic with very high viscosity at temperatures above $1500{ }^{\circ} \mathrm{C} . \mathrm{J} \mathrm{Am}$ Ceram Soc 1998, 81: 3341-3344.

[9] Riedel R, Kleebe HJ, Schönfelder H, et al. A covalent micro/nano-composite resistant to high-temperature oxidation. Nature 1995, 374: 526-528.

[10] Wang Y, Fan Y, Zhang L, et al. Polymer-derived SiAlCN ceramics resist oxidation at $1400{ }^{\circ} \mathrm{C}$. Scripta Mater 2006, 55: 295-297.

[11] Haluschka C, Engel C, Riedel R. Silicon carbonitride ceramics derived from polysilazanes Part II. Investigation of electrical properties. J Eur Ceram Soc 2000, 20: 1365-1374.

[12] Mera G, Riedel R, Poli F, et al. Carbon-rich SiCN ceramics derived from phenyl-containing poly(silylcarbodiimides). $J$ Eur Ceram Soc 2009, 29: 2873-2883.

[13] Wen Q, Yu Z, Riedel R. The fate and role of in situ formed carbon in polymer-derived ceramics. Prog Mater Sci 2020, 109: 100623.

[14] Kleebe HJ, Störmer H, Trassl S, et al. Thermal stability of SiCN ceramics studied by spectroscopy and electron microscopy. Appl Organomet Chem 2001, 15: 858-866.

[15] Gérardin C, Taulelle F, Bahloul D. Pyrolysis chemistry of polysilazane precursors to silicon carbonitride. J Mater Chem 1997, 7: 117-126.

[16] Cordelair J, Greil P. Electrical conductivity measurements as a microprobe for structure transitions in polysiloxane derived Si-O-C ceramics. J Eur Ceram Soc 2000, 20: 1947-1957.
[17] Burns GT, Angelotti TP, Hanneman LF, et al. Alkyl- and arylsilsesquiazanes: Effect of the $\mathrm{R}$ group on polymer degradation and ceramic char composition. J Mater Sci 1987, 22: 2609-2614.

[18] Inagaki M, Kang F. Materials Science and Engineering of Carbon: Fundamentals, 2nd edn. Amsterdam (the Netherlands): Elsevier, 2014.

[19] Li Q, Yin X, Feng L. Dielectric properties of $\mathrm{Si}_{3} \mathrm{~N}_{4}-\mathrm{SiCN}$ composite ceramics in X-band. Ceram Int 2012, 38: 6015-6020.

[20] Li Q, Yin X, Duan W, et al. Improved dielectric properties of PDCs-SiCN by in situ fabricated nano-structured carbons. J Eur Ceram Soc 2017, 37: 1243-1251.

[21] Liu X, Zhang L, Liu Y, et al. Microstructure and the dielectric properties of $\mathrm{SiCN}-\mathrm{Si}_{3} \mathrm{~N}_{4}$ ceramics fabricated via LPCVD/CVI. Ceram Int 2014, 40: 5097-5102.

[22] Xue J, Yin X, Pan H, et al. Crystallization mechanism of CVD $\mathrm{Si}_{3} \mathrm{~N}_{4}-\mathrm{SiCN}$ composite ceramics annealed in $\mathrm{N}_{2}$ atmosphere and their excellent EMW absorption properties. J Am Ceram Soc 2016, 99: 2672-2679.

[23] Xue J, Yin X, Ye F, et al. Microstructure and EMW absorption properties of $\mathrm{CVI} \mathrm{Si}_{3} \mathrm{~N}_{4}-\mathrm{SiCN}$ ceramics with $\mathrm{BN}$ interface annealed in $\mathrm{N}_{2}$ atmosphere. $J$ Am Ceram Soc 2018, 101: 1201-1210.

[24] Xue J, Ren F, Dong Y, et al. $\mathrm{Si}_{3} \mathrm{~N}_{4}-\mathrm{BN}-\mathrm{SiCN}$ ceramics with unique hetero-interfaces for enhancing microwave absorption properties. Ceram Int 2021, 47: 12261-12268.

[25] Li M, Cheng L, Ye F, et al. Tailoring dielectric properties of PDCs-SiCN with bimodal pore-structure by annealing combined with oxidation. J Eur Ceram Soc 2020, 40: 5247-5257.

[26] Duan W, Yin X, Li Q, et al. A review of absorption properties in silicon-based polymer derived ceramics. J Eur Ceram Soc 2016, 36: 3681-3689.

[27] Hörz M, Zern A, Berger F, et al. Novel polysilazanes as precursors for silicon nitride/silicon carbide composites without "free" carbon. J Eur Ceram Soc 2005, 25: 99-110.

[28] Konetschny C, Galusek D, Reschke S, et al. Dense silicon carbonitride ceramics by pyrolysis of cross-linked and warm pressed polysilazane powders. J Eur Ceram Soc 1999, 19: 2789-2796.

[29] Bahloul D, Pereira M, Gerardin C. Pyrolysis chemistry of polysilazane precursors to silicon carbonitride. J Mater Chem 1997, 7: 109-116.

[30] Delhaes P. Chemical vapor deposition and infiltration processes of carbon materials. Carbon 2002, 40: 641-657.

[31] Wang T, Li H, Zhang S, et al. The effect of microstructural evolution on micromechanical behavior of pyrolytic carbon after heat treatment. Diam Relat Mater 2020, 103: 107729.

[32] Zhang $\mathrm{P}$, Zhang L, Yin X. Fabrication of porous $\mathrm{Si}_{3} \mathrm{~N}_{4}-\mathrm{Lu}_{2} \mathrm{Si}_{2} \mathrm{O}_{7}$ composite ceramics. J Mater Sci Technol 2010, 26: 449-453.

[33] Zera E, Nickel W, Kaskel S, et al. Out-of-furnace oxidation of SiCN polymer-derived ceramic aerogel pyrolized at intermediate temperature $\left(600-800{ }^{\circ} \mathrm{C}\right) . \mathrm{J}$ Eur Ceram Soc 
2016, 36: 423-428.

[34] Moro F, Böhni H. Ink-bottle effect in mercury intrusion porosimetry of cement-based materials. J Colloid Interface Sci 2002, 246: 135-149.

[35] Needham D, Kinoshita K, Utoft A. Micro-surface and -interfacial tensions measured using the micropipette technique: Applications in ultrasound-microbubbles, oil-recovery, lung-surfactants, nanoprecipitation, and microfluidics. Micromachines 2019, 10: 105.

[36] Wan J, Gasch MJ, Mukherjee AK. InSitu densification behavior in the pyrolysis consolidation of amorphous $\mathrm{Si}-\mathrm{N}-\mathrm{C}$ bulk ceramics from polymer precursors. $\mathrm{J} \mathrm{Am}$ Ceram Soc 2004, 84: 2165-2169.

[37] O'Reilly EP. The electronic structure of amorphous carbon. J Non-Cryst Solids 1987, 97-98: 1095-1102.

[38] Robertson J. Structural models of a-C and a-C:H. Diam Relat Mater 1995, 4: 297-301.

[39] Zickler GA, Smarsly B, Gierlinger N, et al. A reconsideration of the relationship between the crystallite size La of carbons determined by X-ray diffraction and Raman spectroscopy. Carbon 2006, 44: 3239-3246.

[40] Ferrari AC, Robertson J. Interpretation of Raman spectra of disordered and amorphous carbon. Phys Rev B 2000, 61: 14095-14107.

[41] Trassl S, Motz G, Rössler E, et al. Characterization of the free-carbon phase in precursor-derived $\mathrm{Si}-\mathrm{C}-\mathrm{N}$ ceramics: I, spectroscopic methods. J Am Ceram Soc 2004, 85: 239-244.

[42] Gregori G, Kleebe HJ, Brequel H, et al. Microstructure evolution of precursors-derived $\mathrm{SiCN}$ ceramics upon thermal treatment between 1000 and $1400{ }^{\circ} \mathrm{C}$. J Non-Cryst Solids 2005, 351: 1393-1402.

[43] Gao Y, Mera G, Nguyen H, et al. Processing route dramatically influencing the nanostructure of carbon-rich $\mathrm{SiCN}$ and SiBCN polymer-derived ceramics. Part I: Low temperature thermal transformation. J Eur Ceram Soc 2012, 32: $1857-1866$.

[44] Ma B, Zhu Y, Wang K, et al. PIP process greatly influencing the microstructure and electrical conductivity of polymer-derived SiCN ceramics. J Alloys Compd 2019, 784: 1084-1090.
[45] Hippel ARV. Dielectrics and Waves. London (UK), 1995.

[46] Kingery WD, Bowen HK, Uhlmann DR, et al. Introduction to ceramics. J Electrochem Soc 1977, 124: 152C.

[47] Sihvola A. Mixing rules with complex dielectric coefficients. Subsurf Sens Technol Appl 2000, 1: 393-415.

[48] Bergman DJ. The dielectric constant of a composite material-A problem in classical physics. Phys Rep 1978, 43: 377-407.

[49] Sihvola A, Saastamoinen S, Heiska K. Mixing rules and percolation. Remote Sens Rev 1994, 9: 39-50.

[50] Inagaki M, Park KC, Endo M. Carbonization under pressure. New Carbon Mater 2010, 25: 409-420.

[51] Nomura S, Thomas KM. Some aspects of the generation of coking pressure during coal carbonization. Fuel 1996, 75: 801-808.

[52] Nomura S, Mahoney M, Fukuda K, et al. The mechanism of coking pressure generation I: Effect of high volatile matter coking coal, semi-anthracite and coke breeze on coking pressure and plastic coal layer permeability. Fuel 2010, 89: 1549-1556.

[53] Atkins P, De Paula J. Atkins' Physical Chemistry. Oxford (UK): Oxford University Press, 2010.

[54] Becker A, Hüttinger KJ. Chemistry and kinetics of chemical vapor deposition of pyrocarbon- $\mathrm{V}$ influence of reactor volume/deposition surface area ratio. Carbon 1998, 36: $225-232$.

Open Access This article is licensed under a Creative Commons Attribution 4.0 International License, which permits use, sharing, adaptation, distribution and reproduction in any medium or format, as long as you give appropriate credit to the original author(s) and the source, provide a link to the Creative Commons licence, and indicate if changes were made.

The images or other third party material in this article are included in the article's Creative Commons licence, unless indicated otherwise in a credit line to the material. If material is not included in the article's Creative Commons licence and your intended use is not permitted by statutory regulation or exceeds the permitted use, you will need to obtain permission directly from the copyright holder.

To view a copy of this licence, visit http://creativecommons. org/licenses/by/4.0/. 